\title{
Interaction between Neurogenesis and Hippocampal Memory System: New Vistas
}

\author{
Djoher Nora Abrous ${ }^{1,2}$ and Jan Martin Wojtowicz ${ }^{3}$ \\ ${ }^{1}$ Inserm U862, Bordeaux-F33077, France \\ ${ }^{2}$ Université de Bordeaux, Bordeaux-F33077, France \\ ${ }^{3}$ Department of Physiology, University of Toronto, Medical Sciences Building, Toronto, \\ Ontario M5S 1A8, Canada \\ Correspondence: nora.abrous@bordeaux.inserm.fr; martin.wojtowicz@utoronto.ca
}

During the last decade, the questions on the functionality of adult neurogenesis have changed their emphasis from if to how the adult-born neurons participate in a variety of memory processes. The emerging answers are complex because we are overwhelmed by a variety of behavioral tasks that apparently require new neurons to be performed optimally. With few exceptions, the hippocampal memory system seems to use the newly generated neurons for multiple roles. Adult neurogenesis has given the dentate gyrus new capabilities not previously thought possible within the scope of traditional synaptic plasticity. Looking at these new developments from the perspective of past discoveries, the science of adult neurogenesis has emerged from its initial phase of being, first, a surprising oddity and, later, exciting possibility, to the present state of being an integral part of mainstream neuroscience. The answers to many remaining questions regarding adult neurogenesis will come along only with our growing understanding of the functionality of the brain as a whole. This, in turn, will require integration of multiple levels of organization from molecules and cells to circuits and systems, ultimately resulting in comprehension of behavioral outcomes.

$T^{1}$ he hippocampal formation (HF) is part of an integrated network involved in learning and memory (Eichenbaum 2000, 2001; Morris 2006). However, the precise functional role of the HF is still a matter of debate, as this entity is involved in cognitive mapping, relational memory, configural associations, episodic-like memories, etc. (for review, see Morris 2006). Confounding this complexity, the contribution of the different hippocampal subregions also remains a matter of dispute. Presumably, it is not an accident that among the three main hip- pocampal fields, dentate gyrus (DG), CA3, and $\mathrm{CA} 1$, only the DG is endowed with the capacity for adult neurogenesis. Thus, to understand the role of adult neurogenesis, one may ask what can be expected from lesions of the whole DG. Borrowing from a recent article outlining a neurobiological theory of hippocampal function, we suggest that the DG is not equally involved in all types of hippocampus-dependent memories (Morris 2006). This follows from a parallel arrangement of the two main inputs into the hippocampus, the medial and lateral entorhinal

Editors: Fred H. Gage, Gerd Kempermann, and Hongjun Song

Additional Perspectives on Neurogenesis available at www.cshperspectives.org

Copyright (C) 2015 Cold Spring Harbor Laboratory Press; all rights reserved; doi: 10.1101/cshperspect.a018952

Cite this article as Cold Spring Harb Perspect Biol 2015;7:a018952 
D.N. Abrous and J.M. Wojtowicz

cortices projecting to CA1 and CA3/DG (Fig. 1) (Witter 1993). A lesion in the DG would be expected to disrupt only one of these inputs originating from layer II in the entorhinal cortex. At the functional level, various forms of memory can be disrupted by colchicine lesions of the DG. These include encoding reference spatial memory (Nanry et al. 1989; Xavier et al. 1999; Jeltsch et al. 2001; Nakayama and Sawada 2002), retrieval of reference spatial memory (Nanry et al. 1989), and working memory (Xavier et al. 1999). However, the role of DG is not absolute and some spatial-related tasks, such as odorplace- or object-place-paired associations, are spared (Gilbert and Kesner 2003). Furthermore, the distinction between the roles of DG and CA1

A
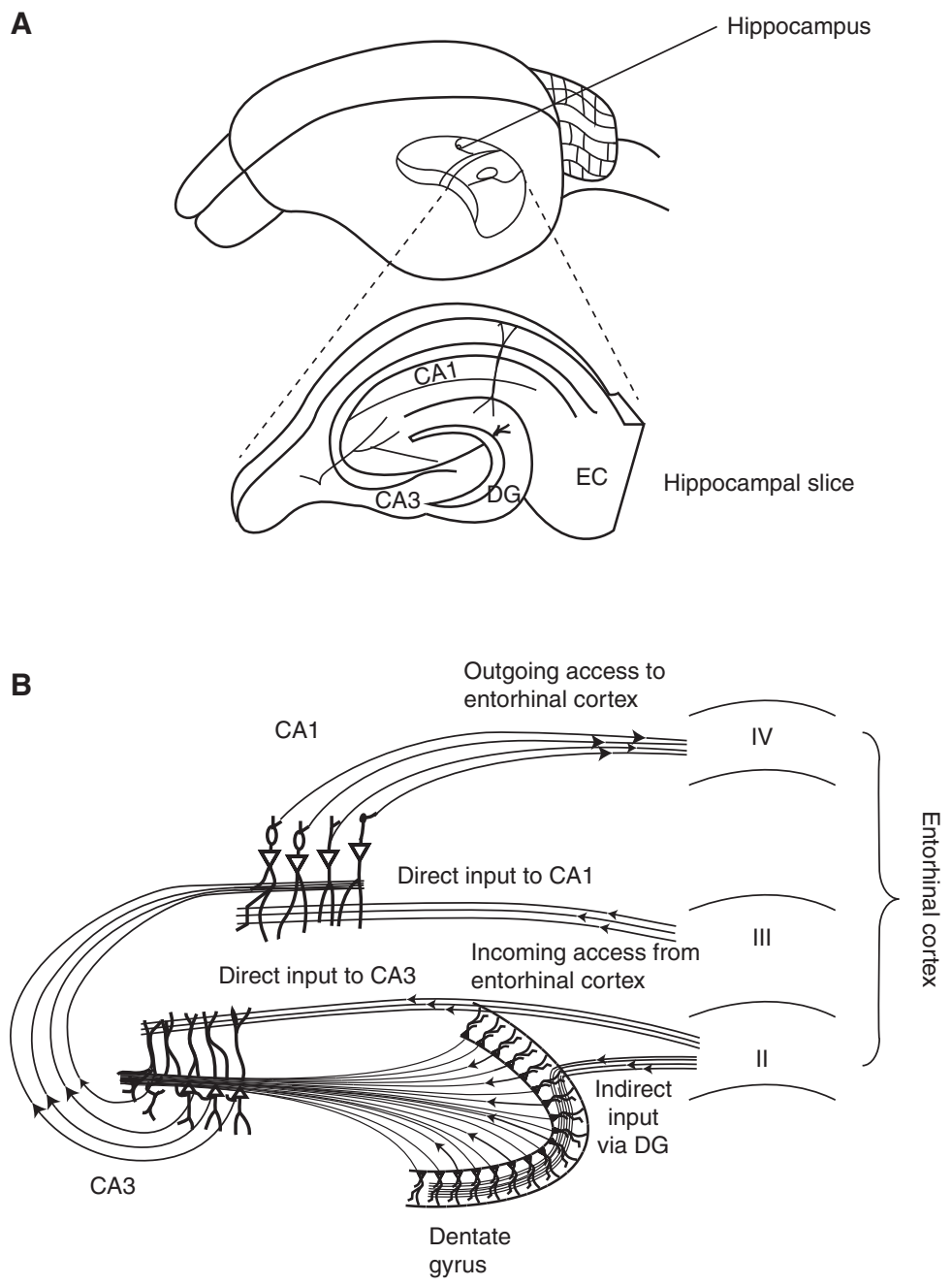

Figure 1. The trisynaptic circuit. $(A)$ The mammalian hippocampus is organized into transverse sections. Each section includes most of the anatomical components comprising the so-called trisynaptic circuit. $(B)$ The first relay in this circuit includes synapses between cortical afferents projecting from the entorhinal cortex (EC) to the dentate gyrus (DG) and the granule neurons arranged in a semicircle. The second relay is located in the CA3 field and consists mainly of the mossy fiber synapses on CA3 pyramidal neurons. The mossy fibers are the axon terminals of the granule neurons. The third relay is in the CA1 field and consists of the axon terminals of CA3 neurons contacting CA1 neurons. This trisynaptic circuit makes up a scaffold for more detailed interconnections within each of the main regions: DG, CA3, and CA1. 
becomes subtle when behavioral tasks involve temporal or spatial pattern separation (PS) (Gilbert et al. 2001). All such experiments involving lesions must take into consideration that, in cases when one region is damaged, the other pathway may compensate for the loss. In support of this explanation, the CA1 place cells, which are corollary of spatial learning, can be formed in spite of selective lesions of the DG (McNaughton et al. 1989; Morris 2006). However, this evidence does not disprove an argument for the involvement of the DG-CA3 pathway, together with the CA3 collateral system, in optimal, normal memory processes (Nakazawa et al. 2002). In summary, taking into account the complexity of hippocampal functioning and considering that newly born granule neurons within DG are a small minority (perhaps 10\%) of the total population, the behavioral consequences of their depletion cannot be easily predicted (Snyder et al. 2001). However, given their strategic location in the gateway of the HF and unique plastic properties, they may play a pivotal role by being more plastic and biasing the input. Since the publication of the first edition of this collection, our improved understanding of adult neurogenesis has led to our increased realization that there may be many functional roles for adult neurogenesis depending on the ages of the animal and the newly born neurons. It is also becoming apparent that adult-born neurons act in tandem with those born during the embryonic or early postnatal period. Finally, as the field of adult neurogenesis research becomes more mature, we begin to realize that its progress is limited by our incomplete understanding of the brain as a whole. In this review, we will outline progress in the light of the complexities and issues that remain to be resolved. There are at least two ways in which neurogenesis and learning have been linked: learning influences neurogenesis in a complex manner and neurogenesis determines learning performance and memory.

\section{INFLUENCE OF LEARNING ON NEUROGENESIS}

Training on learning tasks requiring the HF has been shown to exert a complex influence on distinct steps of neurogenesis: cell survival, proliferation, death, and dendritic growth. We will review the influence of learning on each of these steps separately, keeping in mind that they are interdependent processes.

\section{Effect on Cell Numbers}

\section{Cell Survival}

The effect of associative learning (during trace eye-blink conditioning) has been first examined on the "survival" of newly born cells. In this task, animals have to associate an auditory tone (conditioned stimulus) with a corneal air puff or electrical stimulation (unconditioned stimulus), which is temporally separated by a trace interval. Animals received a single BrdU injection and were submitted to the tasks 1 wk later. The 1-wk delay allows for cell differentiation into neurons, but not to their full maturation because, at this time, the axons and dendritic trees are still under development. Animals killed immediately following trace eye-blink conditioning showed an increase in the number of BrdU-labeled cells (Gould et al. 1999). One week after completion of the task, most newly born cells colabeled with neuronal markers (Gould et al. 1999). The learning-induced increase in neurogenesis was maintained for 2 mo after completion of the task (Leuner et al. 2004). In contrast, learning did not influence the survival of cells generated $3 \mathrm{wk}$ before training or $1 \mathrm{wk}$ after the training experience had ceased, indicating the existence of a critical period (Anderson et al. 2011). The behavioral performances positively correlated with the number of surviving cells, indicating that learning, and not training, rescued the adult-born cells (Leuner et al. 2004). The observed enhancement of cell survival was specific to hippocampus-dependent associative learning, as neurogenesis remained unchanged following active shock avoidance (Van der Borght et al. 2005) and delay-eye-blink conditioning (classically attributed to the cerebellum; Gould et al. 1999). The key difference between the trace- and delay-conditioning procedures is that, in the latter, the conditioned and unconditioned stimuli are not separated in time. These 
D.N. Abrous and J.M. Wojtowicz

results raised the question of whether temporal discontiguity is necessary for enhancing the survival of new neurons. It was found that associative learning increases the survival of new neurons in the adult hippocampus, regardless of temporal contiguity (Leuner et al. 2006). Cell survival was later shown to be regulated by the acquisition and not memory expression (Anderson et al. 2011), the sex of the animals (Dalla et al. 2009), and the degree of task difficulty. Indeed, establishing a contextual conditioned stimulus representation acquired in a single training trial is not sufficient to change the survival of cells born $10 \mathrm{~d}$ before exposure to the task (Pham et al. 2005).

A positive effect of learning on "cell survival" has also been described in the water-maze task. In the pioneer study of Gould, the impact of reference memory was determined using the original training schedule described by Morris. It requires the animals to find a platform in which location remains constant relative to the room cues across trials and days. This procedure is called "spaced training" because trials are distributed over several days. The number of newly born cells, labeled with BrdU 1 wk before exposure to the task, was increased following $4 \mathrm{~d}$ of training (Gould et al. 1999). The observed enhancement of cell survival was specific to spatial learning, as neurogenesis remained unchanged in rats exposed to the task without a platform, but producing the same amount of motor responses (stress group). Furthermore, learning-induced up-regulation of neurogenesis has been specifically attributed to hippocampal functioning, as training on a cued test in the water maze, a hippocampal-independent type of learning, does not modify neurogenesis (Gould et al. 1999). Training animals in a more complex version of the water maze called delayed matching to place (DMP), also increased the survival of cells generated $1 \mathrm{wk}$ before training (Tronel et al. 2012). In this version, the platform is relocated every day, but remains constant through the trials of a given day. This task should not be considered a "pure" working memory task because information is retained and used beyond a single trial (up to $24 \mathrm{~h}$; Steele and Morris 1999). The cognitive demand in this task is considered to be higher than in the classical water-maze protocol. However, learning-induced increase in cell survival was similar when animals were trained using a reference memory or DMP protocol (Tronel et al. 2012).

\section{Effect on Cell Proliferation}

Spatial learning has also been described to induce the "proliferation" of neural precursors. During learning of the water-maze task, two phases can be distinguished: an early phase, during which performance improves rapidly, and a late phase, during which performance stabilizes and reaches an asymptotic level. Döbrössy and colleagues (2003) have shown that the early phase of learning does not modify proliferation, whereas the late phase does. Indeed, when animals were injected with BrdU during the early phase and killed at the end of this phase, learning did not modify BrdU-immunoreactive (IR) cell numbers. In contrast, when animals were injected with BrdU during the late phase of learning and killed $1 \mathrm{~d}$ later, the number of BrdU-labeled cells was increased (Lemaire et al. 2000; Döbrössy et al. 2003). These data were confirmed using specific markers of the cell cycle (Dupret et al. 2007). Learning-induced cell proliferation was not correlated to learning performances (Döbrössy et al. 2003), suggesting that these newly born cells do not directly sustain ongoing learning. These cells survived for at least $5 \mathrm{wk}$ after the animals had acquired the task and differentiated into neurons (Döbrössy et al. 2003). Their function remains to be determined.

\section{Effect on Cell Death}

More surprisingly, spatial learning also decreased the number of newborn cells (Ambrogini et al. 2004). This decline in BrdU cell numbers was not related to stress and/or physical activity because (1) animals were habituated to the pool before training to diminish its stressful component (but see Ehninger and Kempermann 2006), and (2) no change in BrdU cell numbers was observed in yoked animals exposed to the pool, but without the platform. Indeed, in animals injected with BrdU during 
the early phase and killed at the end of the late phase, the number of BrdU-labeled cells decreased. This decrease was specifically induced by the late phase of learning and not by the passage of time (Döbrössy et al. 2003). Even more surprisingly, the decline in newly born cells was correlated with spatial abilities, as rats with the lowest number of BrdU-labeled cells (and, most likely, the highest rates of cell death) had the best memory performances (Döbrössy et al. 2003). These intriguing results, together with the fact that learning also increased the number of newly born cells, may explain why no changes in BrdU-cell numbers were observed in animals injected with BrdU during the entire period of training (van Praag et al. 1999b; Döbrössy et al. 2003).

We have then highlighted that the decline in BrdU-IR cell number resulted from the elimination of cells through a caspase-dependent apoptosis (Dupret et al. 2007). In addition, blocking learning-induced apoptosis by zVAD blocked the learning-induced increased cell survival and impaired memory abilities. Interestingly, the neurons whose survival was increased or decreased by learning were not at the same maturational stage. Indeed, the neurons whose survival was increased were at least $12 \mathrm{~d}$ old, whereas the eliminated ones were $8-9 \mathrm{~d}$ old. Thus, the older newly generated cells survived at the expense of the immature ones that perhaps should "make room.” Newborn neurons are certainly competing for available resources (trophic factors) to survive and/or the neurons survive only if they establish adequate synaptic contacts (inputs/outputs) for learning. If not, neurons are eliminated. This regressive plasticity, resembling the selective stabilization process occurring during development, could, by clearing the network of nonspecific noise caused by superfluous new neurons, enhance the signalto-noise ratio. Supporting this idea, an improvement in the signal-to-noise ratio of motor cortex cells during motor skill learning has been linked to a practice-related improvement in behavioral performance (Kargo and Nitz 2004).

This homeostatic regulation of the number of adult-born neurons also determines learning abilities of aged rats. Indeed, in aged rats with preserved memory functions, spatial learning's influence on the survival of the newly born cells is similar to that observed in young rats: it increases and decreases the survival of newly born neurons depending on their age at the time of learning. In contrast, learning has no effect on the survival of adult-born neurons in aged rats with impaired spatial memory (Drapeau et al. 2007).

Altogether, these results indicate that learning sculpts neoneuronal networks by adding and removing specific populations of cells depending on their maturity and functional relevance. Yet, another scenario has been proposed in which the selection of immature neurons occurs in parallel with cell death of more mature newborn neurons (Ambrogini et al. 2000, 2004). Thus, although both scenarios rely on an active selection process, they differ in the age of the newly born cells, which are selected or killed by learning.

\section{Effect on Dendritic Development}

As described above, the newborn neurons that survive in response to learning may be the ones that are successfully connected. To address this issue, one can examine the dendritic arbor and spine density as measures of the available postsynaptic space that indirectly reflects the presence of inputs (Tronel et al. 2010). Two neuronal populations were examined: (1) the population comprising new neurons generated $1 \mathrm{wk}$ before the start of the training and whose survival was promoted by learning, and (2) the youngest population comprising newly born neurons generated $3 \mathrm{~d}$ before training or during the early phase of training that were spared by the apoptotic wave. For both populations, learning was shown to increase the complexity of the dendritic arbor (and the number of dendritic spines), suggesting an increased connectivity of the adult-born neurons in the DG. In support of this hypothesis, the acceleration of the development of the dendritic arbor of adultborn neurons during epileptic crises is associated with an acceleration of their electrophysiological maturation (Overstreet-Wadiche et al. 2006). The effects of learning on dendritic arbor 
D.N. Abrous and J.M. Wojtowicz

were homeostatically regulated: when cell death was blocked by an antiapoptotic zVAD, there was no effect of learning on dendrites of the youngest and, also, the older population. The effects of learning were maintained over several months. Thus, contrary to what is observed during development, there does not appear to be an overproduction of dendritic branches followed by the elimination of some of them during maturation. In contrast to what is observed for cell numbers, the effects on dendritic tree depended on the cognitive demand because training animals in DMP task further increased dendritic growth. This suggests that various signals affect the branching of the newly generated neurons. Interestingly, there is no critical time window for experience-induced dendritic plasticity of adult-born neurons as spatial learning sculpts the dendritic arbor of adult-born neurons even when they are several months old (Lemaire et al. 2012). The effects of learning are specific for neurons born during adulthood as neurons born during development remained unchanged after learning (Tronel et al. 2010; Lemaire et al. 2012).

\section{Mechanisms}

During development, regressive events have been described at two different stages: (1) after an initial phase of cell proliferation, a fraction of neurons die; and (2) at a later stage, after an initial overproduction of contacts, dendritic branches are eliminated without significant changes in cell numbers. A similar shaping of the neuronal network occurs in the adult brain in response to learning. The first step, occurring during learning of the task, is characterized by an increase in the survival of cells that have been produced before the learning experience. Remarkably, the survival-promoting effect of hippocampal-dependent learning seems to occur during the second week of cellular development. During this "critical period," cells are still immature, but already differentiated as neurons and express immature neuronal markers and physiological neuronal characteristics (Kempermann et al. 2004; Piatti et al. 2006). In contrast, learning does not influence the survival of older
( 2 or $4 \mathrm{mo}$ ) neurons that are well integrated into the network (Lemaire et al. 2012). One hypothesis is that these cells have reached an adequate developmental stage to be "stabilized" by activity-dependent stimuli generated in the course of learning. This is supported by electrophysiological evidence showing that enhanced synaptic activity (obtained by the stimulation of perforant path) enhances cell survival (Bruel-Jungerman et al. 2006) and spinogenesis (Ohkawa et al. 2012).

An activity-dependent process might promote neurogenesis either by GABAergic depolarization (Dieni et al. 2012) and/or by glutamate (Deisseroth et al. 2004). Blockade of $N$-methyl-D-aspartate (NMDA) receptors does not disrupt learning-induced changes in cell numbers (Tronel et al. 2010). These results are consistent with the role of NMDA during the developmental period (Rajan and Cline 1998; Sin et al. 2002; Niell et al. 2004; Prithviraj and Inglis 2008). More recently, $\alpha$-amino-3-hydroxy5-methyl-4-isoxazolepropionic acid (AMPA) receptors have been found to be involved because treating animals with an allosteric AMPA receptor (CX546) rescued learning and learningevoked neurogenesis in racl mutant (Haditsch et al. 2013). Glutamate could regulate neurogenesis through multiple mechanisms. Cell survival and the subsequent dendritic development could be associated with the arrival of glutamatergic inputs acting like a trophic factor governing the selective postsynaptic stabilization (Changeux and Danchin 1976; Rajan and Cline 1998). Indeed, during epileptic crises, the maturation of adult-born neurons is associated with an accelerated arrival of glutamatergic inputs (Overstreet-Wadiche et al. 2006). Alternatively, glutamate could act indirectly on preexisting dentate neurons that have been recently described to innervate newborn neurons (Vivar et al. 2012). The activity dependence could also implicate $\gamma$-aminobutyric acid (GABA) interneurons, which also innervate newborn neurons (Vivar et al. 2012). The newborn cells expressed $\mathrm{GABA}_{\mathrm{A}}$ receptors (Mayo et al. 2005) and GABA regulates adult neurogenesis (Song et al. 2012, 2013). Through enhanced network activity, inputs sculpt den- 
Neurogenesis and Hippocampal Memory System

dritic development by turning on the necessary molecular pathways (Libersat and Duch 2004). Multiple molecular pathways include the following: Racl shown to be involved in learningevoked neurogenesis (Haditsch et al. 2013), the neural activity-induced immediate early gene Gadd45b (Ma et al. 2009), $\beta$-catenin (Gao et al. 2007), Notch (Breunig et al. 2008), and TrkB (Bergami et al. 2008; Danzer et al. 2008), and DISC1 (Duan et al. 2007). Clearly, additional investigations are required to better understand the mechanisms by which learning induces changes in neurogenesis. In particular, emphasis should be placed on the mechanisms that are crucially involved in initiating and directing neuronal production and growth.

Whatever the mechanisms involved, it becomes clear that, as described during ontogenesis, there are several critical periods. So far, in the adult brain, two main critical periods have been identified: one during which newborn cells survive or die, is sensitive to environment $(1-2 \mathrm{wk}$ old), and another one during which the cells show a heightened synaptic plasticity $(3-6 \mathrm{wk}$ old) (Snyder et al. 2001; Ge et al. 2007). In contrast to these relatively short time windows, the dendritic growth and remodeling are thought to occur during prolonged periods and are dependent more on afferent synaptic activity and less on a developmental stage of neurons.

\section{INFLUENCE OF NEUROGENESIS ON LEARNING}

The literature devoted to the specific role of the DG, an area relatively poorly explored compared with the CA3 and CA1, indicates that it is required for different phases of spatial and associative learning. It is also essential for detecting novel spatial arrangements, establishing positional relationships among multiple independent environmental cues, thus allowing the flexible use of acquired information. Finally, it has a unique role in behavioral PS. After the discovery of adult neurogenesis, the role of the new neurons in memory were first examined using a correlational approach and, later on, while new tools were developed, with a causal approach.

\section{Original Data}

\section{Correlations}

Three categories of correlative evidence suggest involvement of adult-born neurons in memory: (1) conditions that enhance neurogenesis also improve learning, (2) conditions that decrease neurogenesis also impair learning, and (3) quantitative correlation between neurogenesis and learning performances. We will only focus on those studies in which memory abilities and neurogenesis have been conducted in the same animals (within-subjects designs).

Most studies evaluating effects of an enriched environment and/or physical activity support the contention that, within a physiological adaptive range, the addition of adultborn neurons may be beneficial for adult brain functioning, particularly for spatial memory. Exposure of mice to an enriched environment or a running wheel increases both the spatial memory ability in the water maze and the number of adult-born neurons in DG (Kempermann et al. 1997, 1998a; Nilsson et al. 1999; van Praag et al. 1999a,b; Brown et al. 2003; Koo et al. 2003; Rossi et al. 2006; Tashiro et al. 2007). In addition, both neurogenesis and spatial memory performances are improved in senescent or middle-aged mice raised in an enriched environment (Kempermann et al. 1998b, 2002). Along the same line, physical activity, whether voluntary (running wheel), or forced (treadmill), was found to restore levels of neurogenesis from old mice to those of young sedentary ones (van Praag et al. 2005; Kronenberg et al. 2006). As expected, this increase in neurogenesis in old exercised animals was associated with an improvement in their abilities in acquiring reference memory in the working memory (WM) compared with sedentary ones (van Praag et al. 2005). In addition, exercise starting at the onset and continued throughout middle age also improves spatial memory and enhances neurogenesis (Marlatt et al. 2012). Further, exposure of rats to an enriched environment during the prenatal period, the early postnatal period (Koo et al. 2003), and adulthood (Nilsson et al. 1999) also increased both neurogenesis and spatial learning abilities in the water maze. 
D.N. Abrous and J.M. Wojtowicz

Beside the effects of enriched environment, others paradigms have been successfully used to show that improvement in memory abilities depends on increased production of new neurons. Lowering corticosterone secretion from midlife (Montaron et al. 2006) or a midlife vitamin A supplementation (Touyarot et al. 2013) for the rest of the animal's life prevents age-related spatial memory deficits and age-related decline in neurogenesis. In a young subject, pharmacological approaches, consisting of peripheral treatment with the cognitive enhancer ginseng (Qiao et al. 2005), the peptidergic drug P21 (Li et al. 2010), the histone acetyltransferases CBP/p300 (Chatterjee et al. 2013), hippocampal gene transfer of VEGF (Cao et al. 2004), blockade of NR2B-containing NMDAR ( $\mathrm{Hu}$ et al. 2008), stimulation of entorhinal cortex (Stone et al. 2011a), or deletion of Toll-like receptors (TLRs) (Okun et al. 2010), all promoted adult neurogenesis and facilitated memory performances in different learning tasks (contextual fear-conditioning paradigm, associative passive avoidance, and water maze).

Conversely, conditions decreasing neurogenesis have been shown to impair learning. Stressful events during the prenatal period caused a lifelong reduction of neurogenesis and disrupted spatial working memory and/or spatial reference memory in the water maze (Lemaire et al. 2000; Koo et al. 2003). Second, manipulation of rearing or adult environment by in utero lipopolysaccharide (LPS) exposure during the last week of gestational life, lead exposure during the first three postnatal weeks, or vitamin A deficiency from adolescence on, reduce neurogenesis and induce deficits in novel object recognition, reference memory performances, and the formation of fear memories (Jaako-Movits and Zharkovsky 2005; Jaako-Movits et al. 2005; Bonnet et al. 2008; Graciarena et al. 2010). Finally, a lesion of the cholinergic septohippocampal pathway (Mohapel et al. 2005) impairs spatial learning and reduces neurogenesis.

Another way to determine the existence of a correlation between learning abilities and neurogenesis has been explored by Kempermann and colleagues. By crossing a strain of mice known to have good learning ability in the WM and high baseline levels of adult neurogenesis $(\mathrm{C} 57 \mathrm{BL} / 6)$ and a strain of mice being poor learners and having low levels of adult neurogenesis (DBA/2), a correlation was found between the number of new neurons generated in the DG and parameters describing the acquisition of the water-maze task (and not remembering it) (Kempermann and Gage 2002). Similar results were obtained in aged rats by taking advantage of the existence of interindividual differences in memory abilities (during acquisition). One month after testing their spatial memory abilities in the water maze, it was found that animals with preserved spatial reference memory, that is, aged-unimpaired rats, showed a higher level of cell proliferation and a higher number of new neurons in comparison to rats with spatial memory impairments, that is, aged-impaired rats (Drapeau et al. 2003). This correlative relation was confirmed in rats (Driscoll et al. 2006), monkeys (Aizawa et al. 2009), and, recently, in humans (Coras et al. 2010), reinforcing its physiological significance.

\section{Causation}

In the first edition of this collection, we highlighted that development of new drugs or transgenic (TG) models should be helpful in showing a causal relationship between memory and neurogenesis. At that time, three methods were used to target the neural progenitor cells in the DG: high-energy irradiation, chemotherapy with mitochondria-associated membrane (MAM), and the inducible glial fibrillary acidic protein (GFAP)-thymidine kinase (TK) TG mice. Since then, new drugs (temozolomide [TMZ], 5-fluorouracil, cyclophosphamide) have been used and many "loss-of-function" TG models based on TK, Cre-lox, and Tet systems were developed to target precursors or immature neurons. Recently, a unique "gain-of-function" model was developed to increase neurogenesis by blocking cell death, and an expected improvement of memory function awaits further study.

The role of adult-born neurons has been more extensively examined on acquiring associative memories ("trace" fear conditioning or 
contextual fear conditioning) and spatial memories (water maze, eight arms, Barnes maze test) (for a recent review, see Koehl and Abrous 2011). To summarize, a clear disruption of trace eye-blink conditioning has been described (Shors et al. 2001, 2002), whereas conflicting results have been reported for contextual fear conditioning. Although some studies reported impairment in generating and/or retrieving contextual fear memory (Saxe et al. 2006; Winocur et al. 2006; Farioli-Vecchioli et al. 2008; Imayoshi et al. 2008; Wojtowicz et al. 2008; Deng et al. 2009; Hernandez-Rabaza et al. 2009), opposite results were found in other studies (Shors et al. 2002; Clark et al. 2008; Dupret et al. 2008; Kitamura et al. 2009).

When testing spatial memory ability, deficits were described in some studies (Snyder et al. 2005; Fan et al. 2007; Dupret et al. 2008; FarioliVecchioli et al. 2008; Imayoshi et al. 2008; Garthe et al. 2009; Lemaire et al. 2012), but not in others (Shors et al. 2002; Madsen et al. 2003; Raber et al. 2004; Meshi et al. 2006; Saxe et al. 2006; Winocur et al. 2006; Wojtowicz et al. 2008). From our own study, based on a model that consisted in selectively ablating adult hippocampal neurogenesis by overexpressing the proapoptotic protein Bax in neuronal precursors on administration of doxycycline, we concluded that adult-born neurons are required for an allocentric (and not egocentric) strategy and for the flexible use of the acquired information (Dupret et al. 2008). Ablating adult hippocampal neurogenesis in this condition resulted in an impairment of acquiring spatial reference memory in the WM. In contrast, cue guidance (finding a visible platform) or egocentric orientation (finding a hidden platform from a constant start position) strategies were spared. In addition, when animals trained to find a hidden platform from a constant start were required to find the same platform from a novel start, deficits were observed. Thus, ablating neurogenesis impaired the ability to use the learned information in a novel situation, indicating that adult-born neurons are critical for flexible, inferential memory expression (Eichenbaum 2001). A similar conclusion was reached using transmission electron microscopy (TEM) and a
Neurogenesis and Hippocampal Memory System

different protocol to assess behavioral flexibility (Garthe et al. 2009). Since then, it has been confirmed that adult-born neurons have an important role for the flexible use of the acquired information (Garthe et al. 2014). Interestingly, this study showed that "not all water mazes are created equal": memory deficits were absent when spatial learning was performed and data analyzed in a conventional way. However, learning deficits were revealed when the cognitive demand of the task was increased and the analysis refined.

\section{New Role for Adult-Born Neurons}

Pattern Separation. The concept of PS predates the acceptance of adult neurogenesis as a bona fide phenomenon in the mammalian brain. Originally, researchers proposed the mechanism for PS as a way to avoid two memories clashing with each other, that is, "memory interference." Memory interference was considered an obstacle in the early efforts to mathematically model the process of learning and memory, and a mechanism, such as PS, was one way to solve the problem. In particular, the "catastrophic" interference in computational networks is the phenomenon in which successive patterns of incoming stimuli overwrite the existing patterns to the point of the latter being unrecognizable (McClelland et al. 1995). Such a computational procedure was thought to resemble a physiological process with newer memories erasing or degrading previously acquired memory traces in the brain (discussed in Wiskott et al. 2006). One computational method to solve the pattern overlap problem and, hence, avoid memory interference is to store patterns in distributed (sparse) networks. If only a few units (among many available) are active with each pattern, the probability that two units are shared between two different patterns is small.

The concept of PS has been applied to various behavioral tasks that require discrimination between stimuli or events presented either simultaneously or in sequence. It is not yet clear how these "behavioral" examples of PS relate to the mechanistic phenomena described above. Many scenarios can be envisaged and we are at 
D.N. Abrous and J.M. Wojtowicz

the initial stage of relating the real-life "behavioral PS" to the neuronal activity within the hippocampal circuits. In a specific case of the hippocampal circuit, one can observe a characteristic pattern of the circuitry in which relatively few cortical neurons send axons toward much more numerous granule neurons in the DG. Such diverging projections of cortical inputs and, consequently, weak excitatory effects on the granule neurons could be inferred on anatomical grounds alone because the input is distributed and, hence, weakened among a large number of target neurons. In addition, the granule neurons are strongly inhibited by GABAergic interneurons, which can further weaken the excitatory input into the DG. Such weak responses have been observed experimentally, that is, only a few granule neurons are found active (i.e., fire action potentials) in behaving animals (see, for review, Rolls 2013). Taking all these computational, anatomical, and physiological factors into account, a theoretical concept of PS has become entrenched in the literature as a factual phenomenon in the hippocampal circuit.

Let us imagine a situation in which two similar events represented by two separate yet similar patterns of neuronal activity are acquired first by the entorhinal cortex and next by the DG via the perforant pathway (Fig. 1). The DG serves as a pattern separator and enables the memories to be encoded independently and unambiguously. Next, these memories can be processed by CA3 for association with either preexisting memories or stored as new information. A physical model can be recreated in any kitchen by directing two fairly uniform streams of water into a strainer. Each stream disperses into multiple strings of small droplets with their unique and semirandom pattern, accentuating subtle differences between the two original streams (Fig. 2). This type of mechanism, avoidance of catastrophic interference by sparsification and, hence, separation of patterns could work without adult neurogenesis. Sheer numbers of granule neurons and their strong inhibition may be sufficient. Nevertheless, the additive neurogenesis has been used in some computational models of the DG and shown to provide an advantage to PS (Appleby and Wiskott 2009).
How mature adult-born neurons achieved this role is again hypothetical. Recently, adultborn neurons have been shown to inhibit the cellular activity of "mature" granule neurons. Indeed, depleting neurogenesis increases the spontaneous $\gamma$ network activity (Lacefield et al. 2010). In contrast, increasing adult neurogenesis reduces the spread of activity and strength of neuronal activation in the DG (Ikrar et al. 2013). Thus, adult-born neurons could enhance the inhibition onto the developmentally generated neurons by providing an inhibitory feedback via interneurons or directly competing with mature granule cells for excitatory input. However, this applies only if the adultborn neurons would participate in signal processing directly by carrying the neural signals encoding the memories. Indeed, we still do not know whether new neurons play a direct role by transmitting or carrying the memory ("carrying the message") or indirect modulation of the transmission ("setting the tone") performed by developmentally generated neurons (Piatti et al. 2013). The distinction between these two hypotheses awaits resolution, along with our better understanding of what exactly the adultborn neurons are doing to influence behavior.

Time Is a Factor in Behavior. Classical models of PS as applied to the hippocampus did not explicitly invoke an "element of time." Yet, in reality, time is an important factor. Discrimination of two similar objects or events occurring simultaneously would presumably involve different mechanisms than discrimination of two events separated by weeks. With our improved understanding of adult neurogenesis, we can also elaborate on our understanding of behavioral PS. Aimone et al. (2006) and Becker and Wojtowicz (2007) serendipitously proposed a mechanism of PS applicable to separation of events in time. In this scenario, separate cohorts of new neurons would encode two events occurring at different times because these neurons are most active and plastic only during a limited time window. Successive cohorts of new neurons would pass through this time window as they grow and develop from the initial state of immature precursors toward less plastic and 

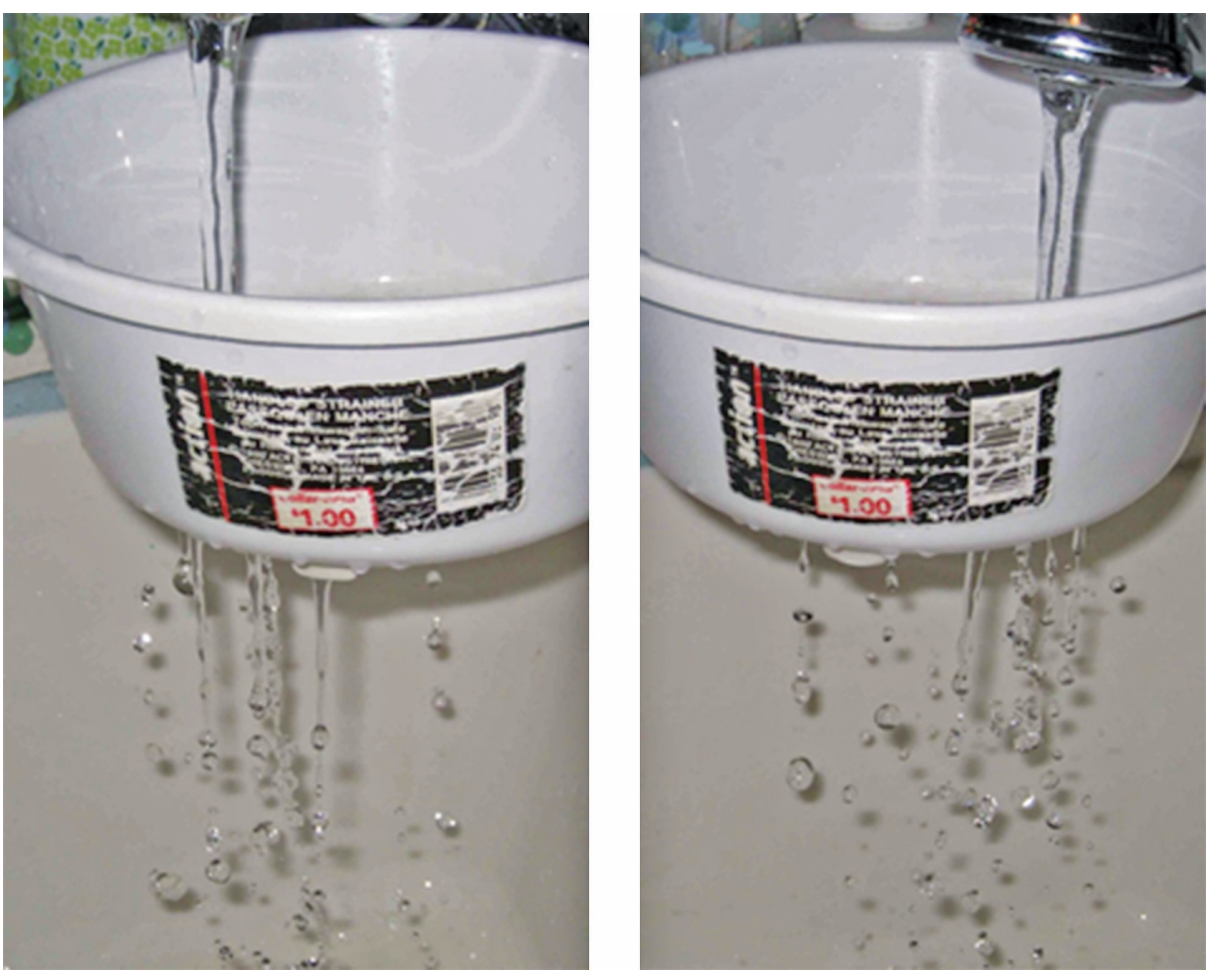

Figure 2. Spaghetti strainer experiment illustrates pattern separation (PS). Each of the small pores at the bottom of the strainer represents a granule neuron transmitting signals from combined afferent inputs. Because of dispersal of the inputs by the random action of each pore, the output at the bottom consists of an array of unique patterns that are quite different from each other although the input streams are similar.

strongly inhibited fully grown granule neurons. As they do so, the cells make themselves available to encode events in the environment. The encoding of events by separate cohorts of new neurons would potentially enable separate storage of memories. However, because some types of learning-dependent plasticities of adult-born neurons extend well into maturity (see above), this scenario may need to be revised (Fig. 3).

Experimental studies are generally vague about time as a factor in behavioral pattern discrimination, but distinct possibilities are beginning to emerge. Clelland et al. (2009) were some of the first to study the contribution of adult neurogenesis to PS in behavioral tasks. They compared normal and adult neurogenesis-deficient mice in two tests (two-choice touch-screen task and a nonmatching to place radial arm maze task) in which spatial separation of stimuli was purposefully varied. Only the tests with small spatial separation showed a need for adult neurogenesis. These data are consistent with the idea that adult neurogenesis is required for discrimination of similar events. In contrast, no difference between control and adult neurogenesis-deficient mice was observed in the standard contextual fear discrimination test (Tronel et al. 2012). However, a difference was revealed when the test was applied repeatedly on several days, hence, a factor of time has been implicated. A similar result was reported using a contextual discrimination task during the course of several days (Whissell et al. 2013). In this case, the difference between control and adult neurogenesis-deficient mice emerged after several days of conditioning. Only the discrimination between similar contexts (similar experimental chambers) and not dissimilar ones was affected. This study is complementary to an earlier one by Sahay and col- 
D.N. Abrous and J.M. Wojtowicz

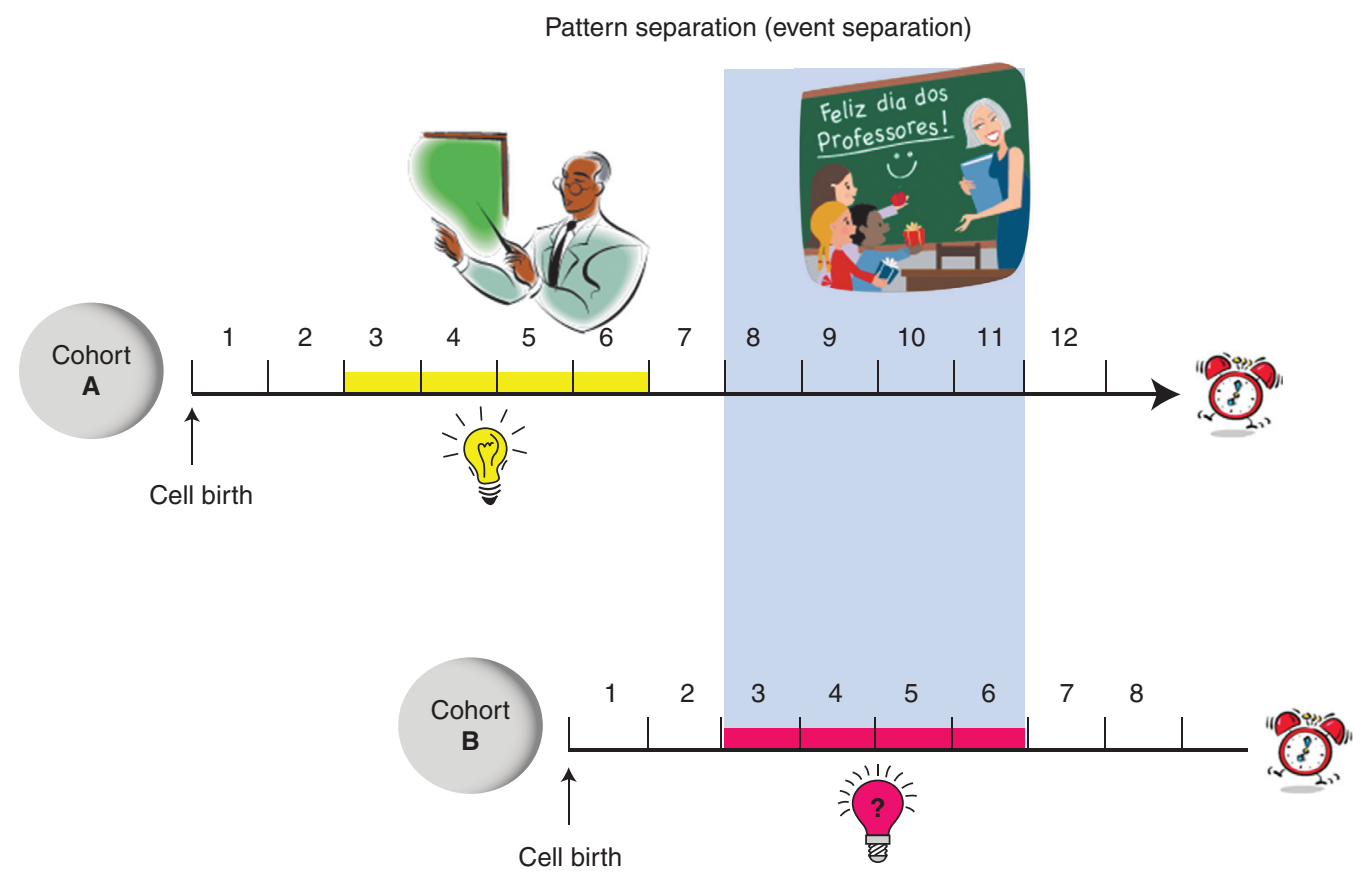

Figure 3. Event separation on the basis of a critical period. Event separation can be considered as a form of behavioral PS because two similar events may have to be tagged in some way to be unambiguously recalled later on. This tagging mechanism may or may not be the same as during the separation of simultaneous events. One possible mechanism, shown here, is based on the known transition of new neurons through the time-dependent developmental window (critical period between 3-6 wk of age). One cohort with a window corresponding to event 1 will be closed during event 2 . However, a second cohort will be open during event 2 and can provide a substrate for encoding.

leagues (2011) who reported improved behavioral PS with the experimental manipulation that increased adult neurogenesis. The question arises whether sparsification is a direct property of immature or mature adult-born neurons. At a network level, individual new neurons at early stages of their development are not well suited to separate incoming afferent signals from the entorhinal cortex because they are relatively devoid of inhibition and, presumably, electrotonically compact and more excitable as compared with the mature granule neurons (Marin-Burgin et al. 2012). These properties would enhance synaptic signal summation, integration, and, consequently, excitation. Increased excitability, together with the enhanced plasticity, would make new neurons more suitable for signal amplification rather than sparsification. At the cellular level, a recent study has shown that a modest reduction of immature adult-born neurons altered the activation of CA3 neurons when coding similar, but not dissimilar (or novel) contexts (Niibori et al. 2012). At the behavioral level, the data obtained so far suggest that immature neurons are not involved in this process (Deng et al. 2013). Deficits appear when training occurs 2 mo (and not earlier) after depleting or increasing adult neurogenesis, suggesting that mature adult-born neurons are involved in PS (Clelland et al. 2009; Sahay et al. 2011; Nakashiba et al. 2012; Tronel et al. 2012; Groves et al. 2013).

Memory Interference. How do we acquire and store new memories without confusing them with many similar events acquired earlier? Hypothetical models considered various pathway configurations that allow for PS during 
memory acquisition (learning) without interference with the previously acquired data (Becker 2005). Such models used the existence of the two inputs into the hippocampus shown in Figure 1. One input enters via the DG and mossy fiber projection to CA3 and the other directly into the CA3 via the perforant pathway. It is thought that new memories are processed via the DG, whereas the preexisting ones are processed via the direct pathway. Convergence of these pathways is thought to be facilitated by recurrent collateral network within CA3 (Treves and Rolls 1992). Again, this scheme does not require the existence of adult neurogenesis, but, with the increased acceptance of neurogenesis among the researchers in the field and experimental evidence showing the benefits of adult neurogenesis in avoiding memory interference, new computational models will likely take it into account. In fact, memory interference may be a result of inadequate PS during memory acquisition or inadequate pattern completion during memory retrieval. Studies of memory interference under conditions of reduced adult neurogenesis show that, indeed, there is a relationship between the two (Wojtowicz et al. 2008; Luu et al. 2012; Winocur et al. 2012). In all cases tested so far, memory interference became more pronounced when adult neurogenesis was reduced. These studies also suggest that adult neurogenesis is relevant to separation of important stimuli from irrelevant, distracting stimuli. A good example of such studies is work by Luu et al. (2012), which showed a recently developed hippocampal memory task depending on olfactory recognition of pairs of odors (Fig. 4). In this task, the animals had to learn a series of odor pairs and, 2 wk later, learn it again under interfering conditions. In the first task, one of the odors in each pair served to indicate a food reward. The spatial location of the food was not a factor because food containers were placed randomly in one of the two food dishes. However, the spatial context contained many visual, tactile, and auditory cues in the cage and around it and, consequently, the learning occurred in a specific sensory/environmental context. The second task (see time line in Fig. 4A) was interfering because some of the odors that previously indicated the food location were blank and paired with new odors, or the previously presented ones that now were food positive. Thus, the animals had to learn the second task while suppressing the previously learned pairing from the first one. The 2-wk separation between the tasks allowed a new population of neurons to "come on line," whereas the previously active ones (at least some of them) should have been phased out by maturation beyond a critical period. The results, illustrated in Figure 4B, show that the animals had no trouble overcoming the interference as long as the contexts for the two tasks were different. In fact, they learned better presumably because of past experience with the task. However, the animals lacking adult neurogenesis (attributable to irradiation 5 wk prior and had no immature neurons) did not benefit from past learning and showed the effects of interference regardless of the context. Control experiments on the same group of animals but trained on a different task that did not include a delay between the first and second training episodes showed no effects of irradiation. In fact, in another study using a task that was repeated several times a day, requiring a working memory, elimination of adult neurogenesis improved the memory performance (Saxe et al. 2007). These results suggest that overcoming of interference in memories at long intervals may be, at least partly, caused by the ability of new neurons to separate the memories in distinct populations of new neurons. But, without allowing time for such separation, the influence may be detrimental.

After reviewing the stage of our knowledge on the possible role of adult-born neurons in these different processes, we will highlight new findings to be taken into account when evaluating the functional role of adult-born neurons.

\section{New Vistas and Future Direction \\ Developmental Versus Adult Neurogenesis}

The interpretation of various studies gets confusing because of inconsistent terminology and wrong assumptions. The role of adult neurogenesis is particularly difficult to determine 
D.N. Abrous and J.M. Wojtowicz

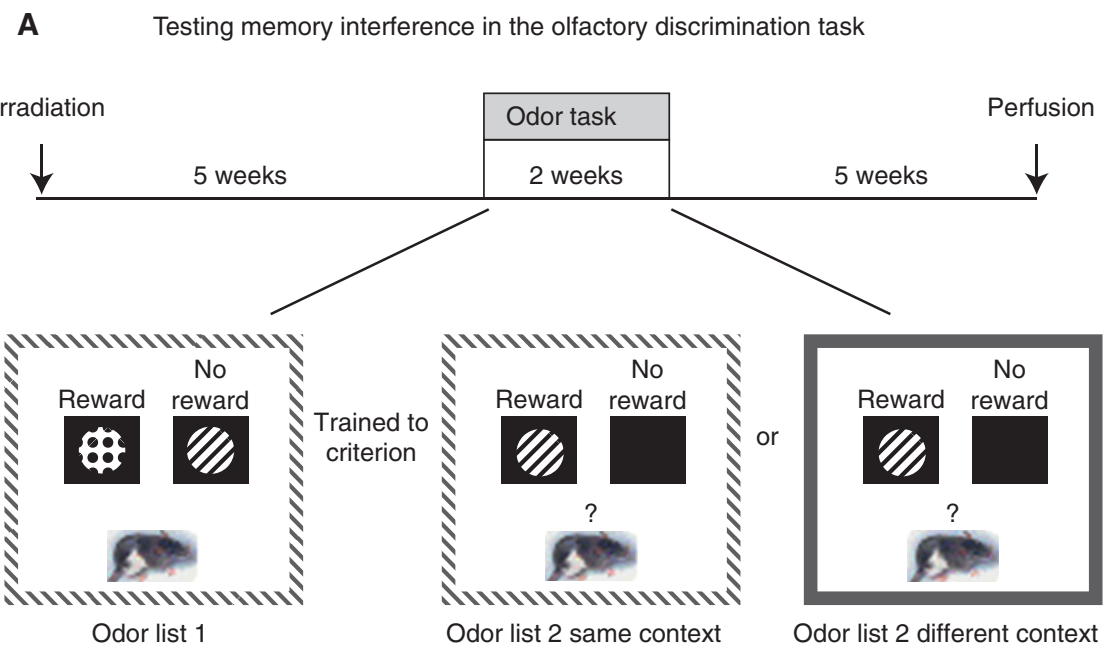

B Neurogenesis is necessary for contextual advantage in a high-interference olfactory task

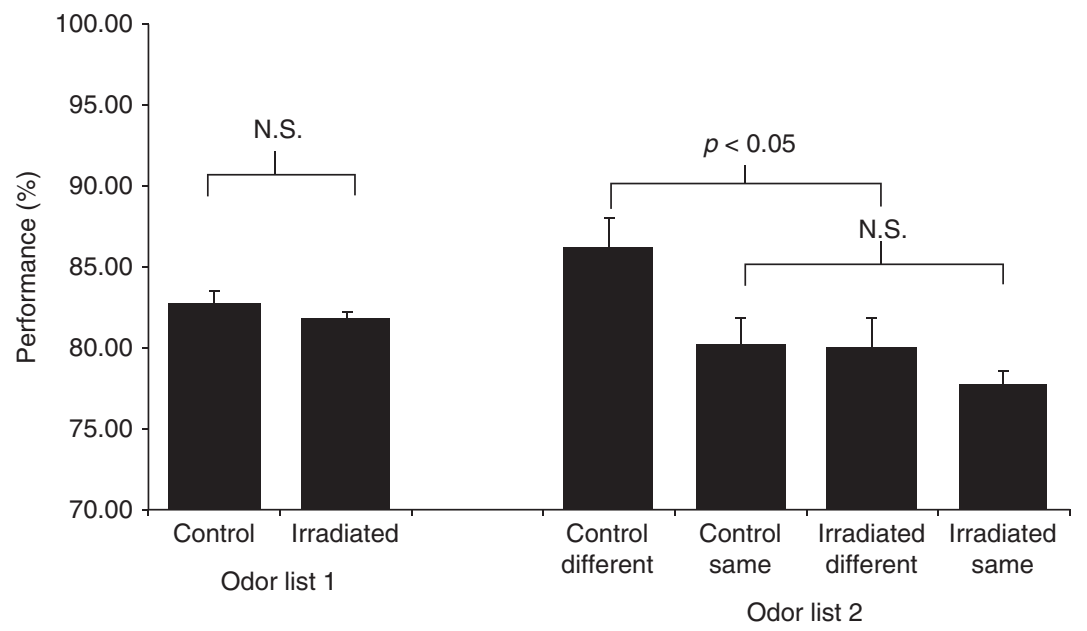

Figure 4. Role of adult-born neurons in memory interference. (A) Time line of an experiment showing memory interference after ablation of adult neurogenesis by irradiation. Each animal was tested twice: first, on a new set of paired olfactory discrimination stimuli (list 1) and, next, on another set (list 2). List 2 was presented in the same or different context as list 1. (B) The results show that memory of list 1 was not changed by irradiation, but the memory of list 2 was made worse regardless of context. Thus, context/memory association was neurogenesis dependent. N.S., Not significant. (Figures based on data in Luu et al. 2012.)

because the term "adult" is often used interchangeably with the rather vague term of "postnatal." Fundamentally, the two types of neurogenesis cannot be the same because they occur in animals of different ages with very different behavioral needs. Postnatal neurogenesis that refers to different ontogenetic developmental stages (pup, neonate, adolescent, also called juvenile) is devoted to overall growth of the DG "from scratch" along with the growth of the whole brain. Note that sexual maturity denotes the beginning of adolescence and occurs $\sim 4-$ 
7 wk postnatal and not the beginning of adulthood (McCutcheon and Marinelli 2009; Spear 2009). This, in turn, is related to behavioral functions of immature animals experiencing everything for the first time. Adult neurogenesis may have an adaptive value rather than an organizational one. In young adult mice and rats ( $>8$ wk, at least), the adult neurogenesis can be seen as superimposed on the lingering postnatal neurogenesis, especially during the transition from juvenile to adult. Although it has not yet been possible to determine when one process ends and the other begins, the juvenile brain is known to be still under "construction," refinement. Pruning, synaptic elimination, synaptic stabilization, and monoaminergic maturation are the signs of network remodeling that renders the juvenile brain so susceptible to stress and drugs (Lupien et al. 2009; McCutcheon and Marinelli 2009; Spear 2009; Karanges et al. 2011; Selemon 2013).

Concerning the DG with it protracted development, even if the cells are generated by the same dentate matrix, and the time course of cell development and expression of stage-specific markers, as well as the overall gross morphology, is similar in juvenile and mature animals (McDonald and Wojtowicz 2005), the environment within which the cells developed and their relation to their environment are different. Recently, it has been shown that the mechanisms regulating developmental and adult neurogenesis in the olfactory bulb are distinct and suggest that adult neurogenesis is not a continuum from developmental neurogenesis (David et al. 2013). Such differences may explain that the number of generated cells (which should influence the noise in the network), the level of competition, and synchrony of developmental steps, as well as the location of the cell bodies that vary according to age of the animal at the time of cell birth. Thus, it is likely that properties and functions of neurons generated in a 1-wk-old pup, 6-wk-old juvenile, 2-mo-old, or 3-yr adult animals are different. The studies investigating these properties with electrophysiological recordings showed, so far, that cells generated in the developing and adult hippocampus display similar glutamate and GABA connectivity
Neurogenesis and Hippocampal Memory System

(Laplagne et al. 2006, 2007). However, this does not exclude the possibility that neuromodulators may act differently on developmental and adult-born neurons. When focusing on their structural plasticity, adult-born, but not developmentally generated, neurons are able to reshape in response to learning (Tronel et al. 2010; Lemaire et al. 2012), suggesting that these dissimilarities confer them different functions. Some studies, indeed, highlighted a specific behavioral signature for neurons born in development (pups or juvenile) versus adulthood (Wei et al. 2011; Nakashiba et al. 2012; Tronel et al. 2014). However, others reported a functional equivalence between these different neuronal populations (Stone et al. 2011b). In sum, as a result of these ambiguities, each study should include a clear time line of animal's age (ontogenetic stage) and cell's age.

\section{Immature Versus Mature Adult-Born Neurons}

Cell age is indeed another source of confusion as adult-born neurons are often called "young neurons" and the others (developmental and mature adult-born neurons) are called mature or old neurons. This confusion is based on the assumption that adult-born neurons are involved in learning only when immature. During a critical time window during immature stage (3-6 wk old), new neurons show a lower activation threshold and increased long-term potentiation (LTP) compared with "mature" neurons (Snyder et al. 2001; Ge et al. 2007). From these observations, it has been postulated that the high synaptic plasticity shown by adult-born neurons during their immature stages confers on them a unique role in processing new information. Then, because they become less excitable as they mature, they are thought to go for early retirement, although they do not die (Alme et al. 2010). However, until now, the assumption that the high level of synaptic plasticity of immature neurons confers them a particular role in memory remains speculative. In addition, the existence of a critical period is not universal as even mature adult-born neurons show dendritic structural plasticity (see above). Finally, in contrast to what was proposed in the early retire- 
D.N. Abrous and J.M. Wojtowicz

ment hypothesis, mature adult-born neurons are permanently functionally integrated into neuronal network. Indeed, by imaging new neurons using Zif268, it has been shown that spatial learning recruited 4-mo-old adult-born neurons (Tronel et al. 2014). Depleting specifically these "old" adult-born neurons (by 1-wk AraC treatment 4 mo before training) delays learning (Lemaire et al. 2012). These data indicating that adult-born neurons do not have a time-dependent role are consistent with the observation that they survive several months (Kempermann et al. 2003). However, the debate is still ongoing as optical controlling revealed time-dependent roles of adult-born neurons (Gu et al. 2012).

A related question is when do adult-born neurons become functionally relevant for hippocampal-dependent memory? Again, the results obtained so far are confusing. One possible interpretation to disambiguate the data is that the time at which new neurons become functionally relevant depends on the complexity of the task. Exploration of a novel environment, one of the simplest forms of learning, has been shown, using Arc, to activate new neurons as early as $4 \mathrm{wk}$ of age (Sandoval et al. 2011). These cells, known to express DCX, were also shown to be important for active place avoidance using knockin DCX ${ }^{\mathrm{DTR}}$ mice (Vukovic et al. 2013). At older cell age (6 wk), new neurons were found to be required for contextual fear conditioning. Indeed, deficits in this task did not manifest until 6 wk after the arrest of neurogenesis (Denny et al. 2011). For spatial learning, the situation is, again, more complex. By imaging activated new neurons using c-Fos, it has been shown that new neurons are recruited from 5 wk of age (Kee et al. 2007). As a consequence, ablation of immature neurons (born 1-7 wk before training) by different means (antimitotic, irradiation, GFAP-TK rats) in rats or mice failed to induce spatial learning deficits (Shors et al. 2002; Snyder et al. 2005; Lemaire et al. 2012; Groves et al. 2013), indicating that they are not involved in ongoing learning. Thus, a fundamental question remains: What are these immature neurons good for? A first element of the response was provided by a study showing that neurons generated $1 \mathrm{wk}$ before spatial learning are recruited during memory retrieval measured 3 wk later (Trouche et al. 2009). Becker and Wojtowicz (2007) proposed that clusters of newly born neurons induce formation of functional neuronal assemblies in CA3. Unlike the mature granule neurons known to fire in sparse and uncorrelated fashion (see above), the activity of newly born neurons could be correlated within the clusters and have a relatively bigger impact on CA3 neurons. Formation of the clusters would precede their ultimate participation in memory encoding by $1-2 \mathrm{wk}$, the time necessary for the cells to grow and mature sufficiently to reach a critical period when the cells are most plastic and, hence, amenable to changes in their strength and dendritic growth. The additional advantage of combined activity of clusters would be the possibility of making a relatively large impact on CA3. The assemblies of CA3 neurons impacted by the clusters of granule neurons would be activated during memory retrieval, presumably as a result of direct perforant path input from entorhinal cortex to CA3. These assemblies could represent memory traces available for further consolidation and for retrieval by the hippocampus, which is always required when a flexible use of the learned information is required (Winocur et al. 2005; Broadbent et al. 2006; Teixeira et al. 2006).

\section{Pattern Completion}

In the last review, we wrote on this subject and we proposed that experiments should continue developing a variety of behavioral tasks because adult neurogenesis is likely to play different roles in different behavioral circumstances. Since then, as reviewed above, a new role of adult-born neurons in behavioral PS has been uncovered. We now propose that we should next focus on pattern completion. Pattern completion at the behavioral/computational level has been defined as the ability of a network to respond to a degraded input pattern with a complete, previously stored pattern. This, in turn, could correspond to the synaptic interactions among the direct and indirect inputs to the CA3, together with the axon collaterals of the CA3 pyramidal neurons (Fig. 5). Impairments 
of the balance between the PS in DG and pattern completion in CA3 may be more important than changes in the absolute magnitude of either one alone. Such balance is known to be upset in the hippocampus during normal aging or pathological states involving changes in the hippocampal circuitry. It has been pointed out that changes in the balance between synaptic inhibition and excitation can lead to excessive pattern completion in CA3 (Wilson et al. 2006). Increased excitability of the brain, presumably caused by reduced GABAergic function, has long been recognized as one of the pathological changes in the aging brain (Stanley and Shetty 2004). This view is consistent with reduced behavioral PS during aging. A particular case of reduced functionality of the perforant path together with inhibitory cholinergic input and reduced activity of inhibitory interneurons in CA3 could potentially enhance collateral excitation within CA3 and make pattern completion too strong relative to PS in the DG. Assuming that the PS is primarily involved in learning the new information and that pattern completion
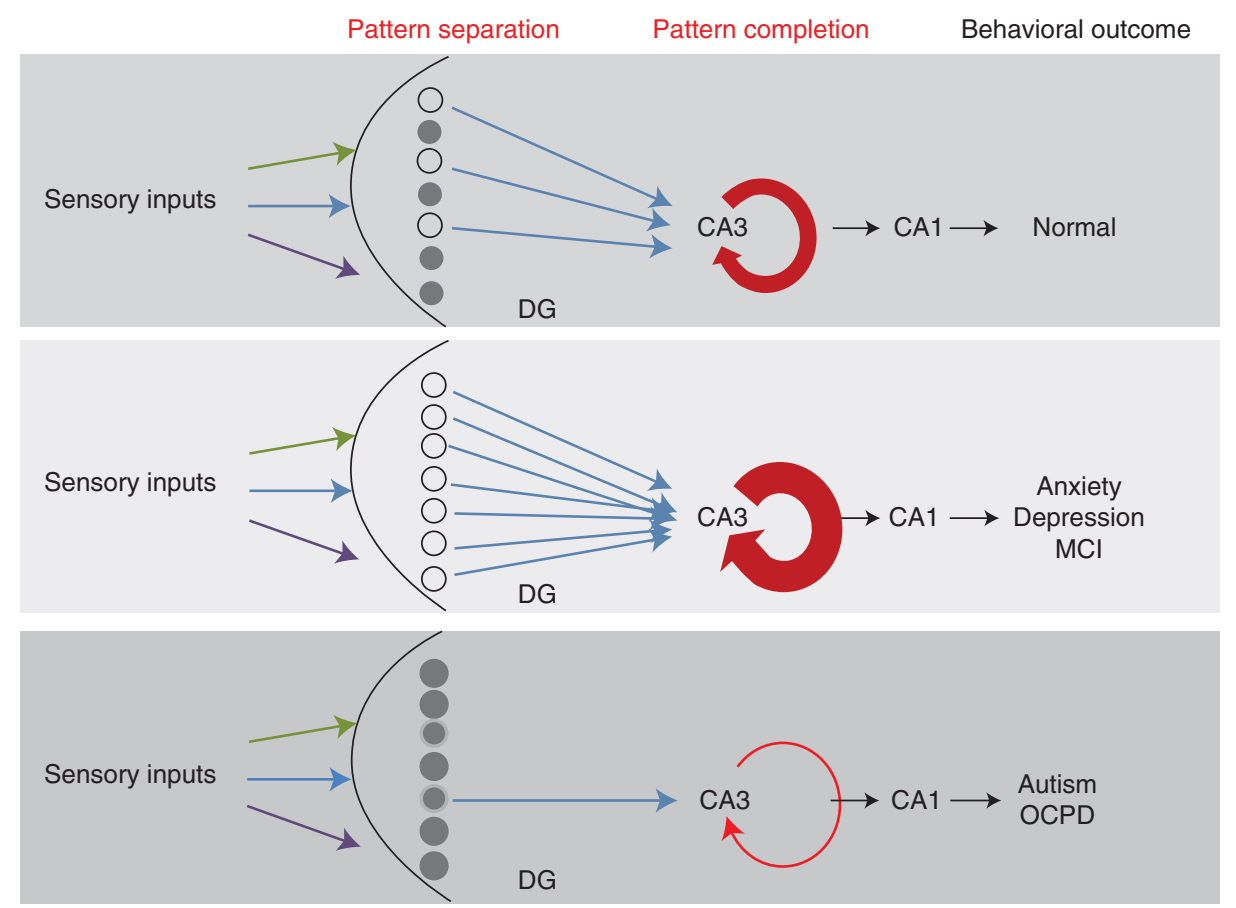

Figure 5. Summary of possible behavioral outcomes resulting from imbalance between pattern separation (PS) and pattern completion. (Top) In control conditions, the dentate gyrus (DG) serves as a pattern separator functioning under a normal inhibitory tone supplied by inhibitory interneurons. Disinhibited granule neurons (open circles) are proportionally fewer than the inhibited granule neurons (filled circles). The loop around CA3 field illustrates normal activity of recurrent collaterals in this region. Their function is to connect the adjacent CA3 neurons and accomplish pattern completion. (Middle) Reduced pattern separation resulting from reduced inhibitory tone, such as during conditions of reduced neurogenesis. An extreme case of all granule neurons being disinhibited is shown. This could result in a loss of PS and exaggerated pattern completion in CA3 as a result of excessive input from mossy fiber afferents. The reduced PS and increased pattern completion could contribute to abnormal hippocampal function in conditions such as anxiety, depression, and mild cognitive impairment (MCI). (Bottom) Increased PS, resulting from increased inhibitory tone because of abnormally enhanced adult neurogenesis. In this case, most granule neurons are inhibited and unable to transmit signals to CA3. PS is extreme and the resulting pattern completion in CA3 is also low. Possible behavioral conditions could include autism, obsessive attention to detail, and obsessive-compulsive disorder (OCPD). 
D.N. Abrous and J.M. Wojtowicz

accounts for recall of previously stored memories, the abnormalities in the circuitry could account for behavioral abnormalities seen in old age, at least, in some individuals. A common expression that old people tend to see what they remember, whereas young ones remember what they see, could therefore be a direct reflection of the age-related changes in cellular networks within the brain. The role of adult-born neurons in this process has yet to be investigated.

\section{CONCLUSIONS}

Within the last decade since the first iteration of this review was completed by us, the field of adult neurogenesis and our understanding of the role of adult neurogenesis in learning and memory has progressed in several directions. The knowledge of the cellular and synaptic properties underlying plasticity and signal processing of the newborn neurons at different cellular ages has been advanced as a result of refined electrophysiological studies. The concept of a critical period for newborn neurons has been extended and widened to encompass various periods in neuronal development. Consequently, the responsiveness of young and mature neurons to learning has been unveiled to be varied depending on the maturational stage of new neurons. A list of neurogenesis-dependent behavioral tests has been widened, so it now appears that almost all hippocampusdependent tests seem to, at least partly, depend on neurogenesis. A reversed dependence of neurogenesis on learning has been shown surprisingly complex. This is emphasized by studies showing that, in some cases, learning can enhance neurogenesis, but in others, it can inhibit it. Wider acceptance of adult neurogenesis resulting from these studies has forced a sometimes uncomfortable merger of traditional hippocampal physiology and computational studies with new concepts and new ideas introduced by this relatively young field. Nevertheless, the field of adult neurogenesis itself has reached a certain maturity, so it is now almost unthinkable to study the role of the hippocampus in learning and memory without considering adult neurogenesis as an integral player. Going forward, we suggest that new vistas, which have opened up as a result of recent research, will guide not only our understanding of the neurogenic process, but also our understanding of the hippocampus as a whole.

\section{ACKNOWLEDGMENTS}

J.M.W. is supported by Operating Grant MOP 119271 from the Canadian Institutes of Health Research (CIHR) and a discovery grant from the Natural Sciences and Engineering Research Council of Canada (NCERC). D.N.A. is supported by the French Institute for Health and Medical Research (Inserm) and the National Agency of Research (ANR) (MemoNeuro ANR2010-BLAN-1408-01). Technical and administrative support provided by Y.-F. Tan to the J.M.W. laboratory is greatly appreciated.

\section{REFERENCES}

Aimone JB, Wiles J, Gage FH. 2006. Potential role for adult neurogenesis in the encoding of time in new memories. Nat Neurosci 9: 723-727.

Aizawa K, Ageyama N, Yokoyama C, Hisatsune T. 2009. Agedependent alteration in hippocampal neurogenesis correlates with learning performance of macaque monkeys. Exp Anim 58: 403-407.

Alme CB, Buzzetti RA, Marrone DF, Leutgeb JK, Chawla MK, Schaner MJ, Bohanick JD, Khoboko T, Leutgeb S Moser EI, et al. 2010. Hippocampal granule cells opt for early retirement. Hippocampus 20: 1109-1123.

Ambrogini P, Cuppini R, Cuppini C, Ciaroni S, Cecchini T, Ferri P, Sartini S, Del Grande P. 2000. Spatial learning affects immature granule cell survival in adult rat dentate gyrus. Neurosci Lett 286: 21-24.

Ambrogini P, Orsini L, Mancini C, Ferri P, Ciaroni S, Cuppini R. 2004. Learning may reduce neurogenesis in adult rat dentate gyrus. Neurosci Lett 359: 13-16.

Anderson ML, Sisti HM, Curlik DM, Shors TJ. 2011. Associative learning increases adult neurogenesis during a critical period. Eur J Neurosci 33: 175-181.

Appleby PA, Wiskott L. 2009. Additive neurogenesis as a strategy for avoiding interference in a sparsely coding dentate gyrus. Network 20: 137-161.

Becker S. 2005. A computational principle for hippocampal learning and neurogenesis. Hippocampus 15: 722-738.

Becker S, Wojtowicz JM. 2007. A model of hippocampal neurogenesis in memory and mood disorders. Trends Cogn Sci 11: 70-76.

Bergami M, Rimondini R, Santi S, Blum R, Gotz M, Canossa M. 2008. Deletion of TrkB in adult progenitors alters newborn neuron integration into hippocampal circuits 
and increases anxiety-like behavior. Proc Natl Acad Sci 105: 15570-15575.

Bonnet E, Touyarot K, Alfos S, Pallet V, Higueret P, Abrous DN. 2008. Retinoic acid restores adult hippocampal neurogenesis and reverses spatial memory deficit in vitamin A deprived rats. PLoS ONE 3: e3487.

Breunig JJ, Sarkisian MR, Arellano JI, Morozov YM, Ayoub AE, Sojitra S, Wang B, Flavell RA, Rakic P, Town T. 2008. Primary cilia regulate hippocampal neurogenesis by mediating sonic hedgehog signaling. Proc Natl Acad Sci 105: 13127-13132.

Broadbent NJ, Squire LR, Clark RE. 2006. Reversible hippocampal lesions disrupt water maze performance during both recent and remote memory tests. Learn Mem 13: 187-191.

Brown JP, Couillard-Despres S, Cooper-Kuhn CM, Winkler J, Aigner L, Kuhn HG. 2003. Transient expression of doublecortin during adult neurogenesis. J Comp Neurol 467: $1-10$.

Bruel-Jungerman E, Davis S, Rampon C, Laroche S. 2006. Long-term potentiation enhances neurogenesis in the adult dentate gyrus. J Neurosci 26: 5888-5893.

Cao L, Jiao X, Zuzga DS, Liu Y, Fong DM, Young D, During MJ. 2004. VEGF links hippocampal activity with neurogenesis, learning and memory. Nat Genet 36: 827-835.

Changeux JP, Danchin A. 1976. Selective stabilisation of developing synapses as a mechanism for the specification of neuronal networks. Nature 264: 705-712.

Chatterjee S, Mizar P, Cassel R, Neidl R, Selvi BR, Mohankrishna DV, Vedamurthy BM, Schneider A, Bousiges O, Mathis C, et al. 2013. A novel activator of CBP/p300 acetyltransferases promotes neurogenesis and extends memory duration in adult mice. J Neurosci 33: 10698 10712.

Clark PJ, Brzezinska WJ, Thomas MW, Ryzhenko NA, Toshkov SA, Rhodes JS. 2008. Intact neurogenesis is required for benefits of exercise on spatial memory but not motor performance or contextual fear conditioning in C57BL/ 6J mice. Neuroscience 155: 1048-1058.

Clelland CD, Choi M, Romberg C, Clemenson GD Jr, Fragniere A, Tyers P, Jessberger S, Saksida LM, Barker RA, Gage FH, et al. 2009. A functional role for adult hippocampal neurogenesis in spatial pattern separation. Science 325: 210-213.

Coras R, Siebzehnrubl FA, Pauli E, Huttner HB, Njunting M, Kobow K, Villmann C, Hahnen E, Neuhuber W, Weigel $\mathrm{D}$, et al. 2010. Low proliferation and differentiation capacities of adult hippocampal stem cells correlate with memory dysfunction in humans. Brain 133: 3359-3372.

Dalla C, Papachristos EB, Whetstone AS, Shors TJ. 2009. Female rats learn trace memories better than male rats and consequently retain a greater proportion of new neurons in their hippocampi. Proc Natl Acad Sci 106: 29272932.

Danzer SC, Kotloski RJ, Walter C, Hughes M, McNamara JO. 2008. Altered morphology of hippocampal dentate granule cell presynaptic and postsynaptic terminals following conditional deletion of TrkB. Hippocampus 18: 668-678.

David LS, Schachner M, Saghatelyan A. 2013. The extracellular matrix glycoprotein tenascin-R affects adult but not
Neurogenesis and Hippocampal Memory System

developmental neurogenesis in the olfactory bulb. J Neurosci 33: 10324-10339.

Deisseroth K, Singla S, Toda H, Monje M, Palmer TD, Malenka RC. 2004. Excitation-neurogenesis coupling in adult neural stem/progenitor cells. Neuron 42: 535-552.

Deng W, Saxe MD, Gallina IS, Gage FH. 2009. Adult-born hippocampal dentate granule cells undergoing maturation modulate learning and memory in the brain. J Neurosci 29: 13532-13542.

Deng W, Mayford M, Gage FH. 2013. Selection of distinct populations of dentate granule cells in response to inputs as a mechanism for pattern separation in mice. eLife 2: e00312.

Denny CA, Burghardt NS, Schachter DM, Hen R, Drew MR. 2011. 4- to 6-week-old adult-born hippocampal neurons influence novelty-evoked exploration and contextual fear conditioning. Hippocampus 22: 1188-1201.

Dieni CV, Chancey JH, Overstreet-Wadiche LS. 2012. Dynamic functions of GABA signaling during granule cell maturation. Front Neural Circuits 6: 113.

Döbrössy MDE, Aurousseau C, Le Moal M, Piazza PV, Abrous DN. 2003. Differential effects of learning on neurogenesis: Learning increases or decreases the number of newly born cells depending on their birth date. Mol Psychiatry 8: 974-982.

Drapeau E, Mayo W, Aurousseau C, Le Moal M, Piazza PV, Abrous DN. 2003. Spatial memory performances of aged rats in the water maze predict levels of hipppocampal neurogenesis. Proc Natl Acad Sci 100: 14385-14390.

Drapeau E, Montaron MF, Aguerre S, Abrous DN. 2007. Learning-induced survival of new neurons depends on the cognitive status of aged rats. J Neurosci 27: 60376044.

Driscoll I, Howard SR, Stone JC, Monfils MH, Tomanek B, Brooks WM, Sutherland RJ. 2006. The aging hippocampus: A multi-level analysis in the rat. Neuroscience 139: $1173-1185$.

Duan X, Chang JH, Ge S, Faulkner RL, Kim JY, Kitabatake Y, Liu XB, Yang CH, Jordan JD, Ma DK, et al. 2007. Disrupted-in-schizophrenia 1 regulates integration of newly generated neurons in the adult brain. Cell 130: 11461158.

Dupret D, Fabre A, Dobrössy M, Panetier A, Rodriguez JJ, Lemaire V, Oliet SHR, Piazza PV, Abrous DN. 2007. Spatial learning depends on both the addition and removal of new hippocampal neurons. PLoS Biol 5: e214.

Dupret D, Revest JM, Koehl M, Ichas F, De Giorgi F, Costet P, Abrous DN, Piazza PV. 2008. Spatial relational memory requires hippocampal adult neurogenesis. PLOS ONE 3: e1959.

Ehninger D, Kempermann G. 2006. Paradoxical effects of learning the Morris water maze on adult hippocampal neurogenesis in mice may be explained by a combination of stress and physical activity. Genes Brain Behav 5: 2939.

Eichenbaum H. 2000. A cortical-hippocampal system for declarative memory. Nat Rev Neurosci 1: 41-50.

Eichenbaum H. 2001. The hippocampus and declarative memory: Cognitive mechanisms and neural codes. Behav Brain Res 127: 199-207. 
D.N. Abrous and J.M. Wojtowicz

Fan Y, Liu E, Weinstein PR, Fike JR, Liu J. 2007. Environmental enrichment enhances neurogenesis and improve functional outcome after cranial irradiation. Eur J Neurosci 25: 38-46.

Farioli-Vecchioli S, Saraulli D, Costanzi M, Pacioni S, Cina I, Aceti M, Micheli L, Bacci A, Cestari V, Tirone F. 2008. The timing of differentiation of adult hippocampal neurons is crucial for spatial memory. PLoS Biol 6: e246.

Gao X, Arlotta P, Macklis JD, Chen J. 2007. Conditional knock-out of $\beta$-catenin in postnatal-born dentate gyrus granule neurons results in dendritic malformation. $J$ Neurosci 27: 14317-14325.

Garthe A, Behr J, Kempermann G. 2009. Adult-generated hippocampal neurons allow the flexible use of spatially precise learning strategies. PLoS ONE 4: e5464.

Garthe A, Huang Z, Kaczmarek L, Filipkowski RK, Kempermann G. 2014. Not all water mazes are created equal: Cyclin D2 knockout mice with constitutively suppressed adult hippocampal neurogenesis do show specific spatial learning deficits. Genes Brain Behav 13: 357-364.

Ge S, Yang CH, Hsu KS, Ming GL, Song H. 2007. A critical period for enhanced synaptic plasticity in newly generated neurons of the adult brain. Neuron 54: 559-566.

Gilbert PE, Kesner RP. 2003. Localization of function within the dorsal hippocampus: The role of the CA3 subregion in paired-associate learning. Behav Neurosci 117: 13851394.

Gilbert PE, Kesner RP, Lee I. 2001. Dissociating hippocampal subregions: Double dissociation between dentate gyrus and CA1. Hippocampus 11: 626-636.

Gould E, Beylin A, Tanapat P, Reeves A, Shors TJ. 1999. Learning enhances adult neurogenesis in the hippocampal formation. Nat Neurosci 2: 260-265.

Graciarena M, Depino AM, Pitossi FJ. 2010. Prenatal inflammation impairs adult neurogenesis and memory related behavior through persistent hippocampal TGF $\beta_{1}$ downregulation. Brain Behav Immun 24: 1301-1309.

Groves JO, Leslie I, Huang GJ, McHugh SB, Taylor A, Mott R, Munafo M, Bannerman DM, Flint J. 2013. Ablating adult neurogenesis in the rat has no effect on spatial processing: Evidence from a novel pharmacogenetic model. PLoS Genet 9: e1003718.

Gu Y, Arruda-Carvalho M, Wang J, Janoschka SR, Josselyn SA, Frankland PW, Ge S. 2012. Optical controlling reveals time-dependent roles for adult-born dentate granule cells. Nat Neurosci 15: 1700-1706.

Haditsch U, Anderson MP, Freewoman J, Cord B, Babu H, Brakebusch C, Palmer TD. 2013. Neuronal Rac1 is required for learning-evoked neurogenesis. J Neurosci 33: 12229-12241.

Hernandez-Rabaza V, Llorens-Martin M, Velazquez-Sanchez C, Ferragud A, Arcusa A, Gumus HG, GomezPinedo U, Perez-Villalba A, Rosello J, Trejo JL, et al 2009. Inhibition of adult hippocampal neurogenesis disrupts contextual learning but spares spatial working memory, long-term conditional rule retention and spatial reversal. Neuroscience 159: 59-68.

Hu M, Sun YJ, Zhou QG, Chen L, Hu Y, Luo CX, Wu JY, Xu JS, Li LX, Zhu DY. 2008. Negative regulation of neurogenesis and spatial memory by NR2B-containing NMDA receptors. J Neurochem 106: 1900-1913.
Ikrar T, Guo N, He K, Besnard A, Levinson S, Hill A, Lee HK, Hen R, Xu X, Sahay A. 2013. Adult neurogenesis modifies excitability of the dentate gyrus. Front Neural Circuits 7: 204.

Imayoshi I, Sakamoto M, Ohtsuka T, Takao K, Miyakawa T, Yamaguchi M, Mori K, Ikeda T, Itohara S, Kageyama R. 2008. Roles of continuous neurogenesis in the structural and functional integrity of the adult forebrain. $\mathrm{Nat} \mathrm{Neu}$ rosci 11: 1153-1161.

Jaako-Movits K, Zharkovsky A. 2005. Impaired fear memory and decreased hippocampal neurogenesis following olfactory bulbectomy in rats. Eur J Neurosci 22: 28712878.

Jaako-Movits K, Zharkovsky T, Romantchik O, Jurgenson M, Merisalu E, Heidmets LT, Zharkovsky A. 2005. Developmental lead exposure impairs contextual fear conditioning and reduces adult hippocampal neurogenesis in the rat brain. Int J Dev Neurosci 23: 627-635.

Jeltsch H, Bertrand F, Lazarus C, Cassel JC. 2001. Cognitive performances and locomotor activity following dentate granule cell damage in rats: Role of lesion extent and type of memory tested. Neurobiol Learn Mem 76: 81-105.

Karanges E, Li KM, Motbey C, Callaghan PD, Katsifis A, McGregor IS. 2011. Differential behavioural and neurochemical outcomes from chronic paroxetine treatment in adolescent and adult rats: A model of adverse antidepressant effects in human adolescents? Int J Neuropsychopharmacol 14: 491-504.

Kargo WJ, Nitz DA. 2004. Improvements in the signal-tonoise ratio of motor cortex cells distinguish early versus late phases of motor skill learning. J Neurosci 24: 55605569.

Kee N, Teixeira CM, Wang AH, Frankland PW. 2007. Preferential incorporation of adult-generated granule cells into spatial memory networks in the dentate gyrus. Nat Neurosci 10: 355-362.

Kempermann G, Gage FH. 2002. Genetic determinants of adult hippocampal neurogenesis correlate with acquisition, but not probe trial performance, in the water maze task. Eur J Neurosci 16: 129-136.

Kempermann G, Kuhn HG, Gage FH. 1997. Genetic influence on neurogenesis in the dentate gyrus of adult mice. Proc Natl Acad Sci 94: 10409-10414.

Kempermann G, Brandon EP, Gage FH. 1998a. Environmental stimulation of $129 / \mathrm{SvJ}$ mice causes increased cell proliferation and neurogenesis in the adult dentate gyrus. Curr Biol 8: 939-942.

Kempermann G, Kuhn HG, Gage FH. 1998b. Experienceinduced neurogenesis in the senescent dentate gyrus. $J$ Neurosci 18: 3206-3212.

Kempermann G, Gast D, Gage FH. 2002. Neuroplasticity in old age: Sustained fivefold induction of hippocampal neurogenesis by long-term environmental enrichment. Ann Neurol 52: 135-143.

Kempermann G, Gast D, Kronenberg G, Yamaguchi M, Gage FH. 2003. Early determination and long-term persistence of adult-generated new neurons in the hippocampus of mice. Development 130: 391-399.

Kempermann G, Jessberger S, Steiner B, Kronenberg G. 2004. Milestones of neuronal development in the adult hippocampus. Trends Neurosci 27: 447-452. 
Kitamura T, Saitoh Y, Takashima N, Murayama A, Niibori Y, Ageta H, Sekiguchi M, Sugiyama H, Inokuchi K. 2009. Adult neurogenesis modulates the hippocampus-dependent period of associative fear memory. Cell 139: 814827.

Koehl M, Abrous DN. 2011. A new chapter in the field of memory: Adult hippocampal neurogenesis. Eur J Neurosci 33: 1101-1114.

Koo JW, Park CH, Choi SH, Kim NJ, Kim HS, Choe JC, Suh YH. 2003. The postnatal environment can counteract prenatal effects on cognitive ability, cell proliferation, and synaptic protein expression. FASEB J 17: 1556-1558.

Kronenberg G, Bick-Sander A, Bunk E, Wolf C, Ehninger D, Kempermann G. 2006. Physical exercise prevents age-related decline in precursor cell activity in the mouse dentate gyrus. Neurobiol Aging 27: 1505-1513.

Lacefield CO, Itskov V, Reardon T, Hen R, Gordon JA. 2010 Effects of adult-generated granule cells on coordinated network activity in the dentate gyrus. Hippocampus 22: 106-116.

Laplagne DA, Esposito MS, Piatti VC, Morgenstern NA, Zhao C, van Praag H, Gage FH, Schinder AF. 2006. Functional convergence of neurons generated in the developing and adult hippocampus. PLoS Biol 4: e409.

Laplagne DA, Kamienkowski JE, Esposito MS, Piatti VC, Zhao C, Gage FH, Schinder AF. 2007. Similar GABAergic inputs in dentate granule cells born during embryonic and adult neurogenesis. Eur J Neurosci 25: 2973-2981.

Lemaire V, Koehl M, Le Moal M, Abrous DN. 2000. Prenatal stress produces learning deficits associated with an inhibition of neurogenesis in the hippocampus. Proc Natl Acad Sci 97: 11032-11037.

Lemaire V, Tronel S, Montaron MF, Fabre A, Dugast E, Abrous DN. 2012. Long-lasting plasticity of hippocampal adult-born neurons. J Neurosci 32: 3101-3108.

Leuner B, Mendolia-Loffredo S, Kozorovitskiy Y, Samburg D, Gould E, Shors TJ. 2004. Learning enhances the survival of new neurons beyond the time when the hippocampus is required for memory. J Neurosci 24: $7477-$ 7481.

Leuner B, Waddell J, Gould E, Shors TJ. 2006. Temporal discontiguity is neither necessary nor sufficient for learning-induced effects on adult neurogenesis. J Neurosci 26: 13437-13442.

Li B, Wanka L, Blanchard J, Liu F, Chohan MO, Iqbal K, Grundke-Iqbal I. 2010. Neurotrophic peptides incorporating adamantane improve learning and memory, promote neurogenesis and synaptic plasticity in mice. FEBS Lett 584: 3359-3365.

Libersat F, Duch C. 2004. Mechanisms of dendritic maturation. Mol Neurobiol 29: 303-320.

Lupien SJ, McEwen BS, Gunnar MR, Heim C. 2009. Effects of stress throughout the lifespan on the brain, behaviour and cognition. Nat Rev Neurosci 10: 434-445.

Luu P, Sill OC, Gao L, Becker S, Wojtowicz JM, Smith DM. 2012. The role of adult hippocampal neurogenesis in reducing interference. Behav Neurosci 126: 381-391.

Ma DK, Jang MH, Guo JU, Kitabatake Y, Chang L, PowAnpongkul N, Flavell RA, Lu B, Ming GL, Song H. 2009. Neuronal activity-induced Gadd45b promotes epi-
Neurogenesis and Hippocampal Memory System

genetic DNA demethylation and adult neurogenesis. Science 323: 1074-1077.

Madsen TM, Kristjansen PE, Bolwig TG, Wortwein G. 2003. Arrested neuronal proliferation and impaired hippocampal function following fractionated brain irradiation in the adult rat. Neuroscience 119: 635-642.

Marin-Burgin A, Mongiat LA, Pardi MB, Schinder AF. 2012. Unique processing during a period of high excitation/ inhibition balance in adult-born neurons. Science 335: $1238-1242$.

Marlatt MW, Potter MC, Lucassen PJ, van Praag H. 2012. Running throughout middle-age improves memory function, hippocampal neurogenesis, and BDNF levels in female C57BL/6J mice. Dev Neurobiol 72: 943-952.

Mayo W, Lemaire V, Malaterre J, Rodriguez JJ, Cayre M, Stewart MG, Kharouby M, Rougon G, Le Moal M, Piazza $\mathrm{PV}$, et al. 2005. Pregnenolone sulfate enhances neurogenesis and PSA-NCAM in young and aged hippocampus. Neurobiol Aging 26: 103-114.

McClelland JL, McNaughton BL, O’Reilly RC. 1995. Why there are complementary learning systems in the hippocampus and neocortex: Insights from the successes and failures of connectionist models of learning and memory. Psychol Rev 102: 419-457.

McCutcheon JE, Marinelli M. 2009. Age matters. Eur J Neurosci 29: 997-1014.

McDonald HY, Wojtowicz JM. 2005. Dynamics of neurogenesis in the dentate gyrus of adult rats. Neurosci Lett 385: 70-75.

McNaughton BL, Barnes CA, Meltzer J, Sutherland RJ. 1989. Hippocampal granule cells are necessary for normal spatial learning but not for spatially selective pyramidal cell discharge. Exp Brain Res 76: 485-496.

Meshi D, Drew MR, Saxe M, Ansorge MS, David D, Santarelli L, Malapani C, Moore H, Hen R. 2006. Hippocampal neurogenesis is not required for behavioral effects of environmental enrichment. Nat Neurosci 9: 729-731.

Mohapel P, Leanza G, Kokaia M, Lindvall O. 2005. Forebrain acetylcholine regulates adult hippocampal neurogenesis and learning. Neurobiol Aging 26: 939-946.

Montaron MF, Drapeau E, Dupret D, Kitchener P, Aurousseau C, Le MM, Piazza PV, Abrous DN. 2006. Lifelong corticosterone level determines age-related decline in neurogenesis and memory. Neurobiol Aging 27: 645-654.

Morris RG. 2006. Elements of a neurobiological theory of hippocampal function: The role of synaptic plasticity, synaptic tagging and schemas. Eur J Neurosci 23: 28292846.

Nakashiba T, Cushman JD, Pelkey KA, Renaudineau S, Buhl DL, McHugh TJ, Rodriguez B, Chittajallu VR, Iwamoto KS, McBain CJ, et al. 2012. Young dentate granule cells mediate pattern separation, whereas old granule cells facilitate pattern completion. Cell 149: 188-201.

Nakayama T, Sawada T. 2002. Involvement of microtubule integrity in memory impairment caused by colchicine. Pharmacol Biochem Behav 71: 119-138.

Nakazawa K, Quirk MC, Chitwood RA, Watanabe M, Yeckel MF, Sun LD, Kato A, Carr CA, Johnston D, Wilson MA, et al. 2002. Requirement for hippocampal CA3 NMDA receptors in associative memory recall. Science 297: 211218. 
D.N. Abrous and J.M. Wojtowicz

Nanry KP, Mundy WR, Tilson HA. 1989. Colchicine-induced alterations of reference memory in rats: Role of spatial versus non-spatial task components. Behav Brain Res 35: 45-53.

Niell CM, Meyer MP, Smith SJ. 2004. In vivo imaging of synapse formation on a growing dendritic arbor. Nat Neurosci 7: 254-260.

Niibori Y, Yu TS, Epp JR, Akers KG, Josselyn SA, Frankland PW. 2012. Suppression of adult neurogenesis impairs population coding of similar contexts in hippocampal CA3 region. Nat Commun 3: 1253.

Nilsson M, Perfilieva E, Johansson U, Orwar O, Eriksson PS. 1999. Enriched environment increases neurogenesis in the adult rat dentate gyrus and improves spatial memory. J Neurobiol 39: 569-578.

Ohkawa N, Saitoh Y, Tokunaga E, Nihonmatsu I, Ozawa F, Murayama A, Shibata F, Kitamura T, Inokuchi K. 2012. Spine formation pattern of adult-born neurons is differentially modulated by the induction timing and location of hippocampal plasticity. PLoS ONE 7: e45270.

Okun E, Griffioen K, Barak B, Roberts NJ, Castro K, Pita MA, Cheng A, Mughal MR, Wan R, Ashery U, et al. 2010. Toll-like receptor 3 inhibits memory retention and constrains adult hippocampal neurogenesis. Proc Natl Acad Sci 107: 15625-15630.

Overstreet-Wadiche LS, Bromberg DA, Bensen AL, Westbrook GL. 2006. Seizures accelerate functional integration of adult-generated granule cells. J Neurosci 26: 4095-4103.

Pham K, McEwen BS, LeDoux JE, Nader K. 2005. Fear learning transiently impairs hippocampal cell proliferation. Neuroscience 130: 17-24.

Piatti VC, Esposito MS, Schinder AF. 2006. The timing of neuronal development in adult hippocampal neurogenesis. Neuroscientist 12: 463-468.

Piatti VC, Ewell LA, Leutgeb JK. 2013. Neurogenesis in the dentate gyrus: Carrying the message or dictating the tone. Front Neurosci 7: 50.

Prithviraj R, Inglis FM. 2008. Expression of the N-methyl-Daspartate receptor subunit NR3B regulates dendrite morphogenesis in spinal motor neurons. Neuroscience 155: $145-153$.

Qiao C, Den R, Kudo K, Yamada K, Takemoto K, Wati H, Kanba S. 2005. Ginseng enhances contextual fear conditioning and neurogenesis in rats. Neurosci Res 51:31-38.

Raber J, Rola R, LeFevour A, Morhardt D, Curley J, Mizumatsu S, VandenBerg SR, Fike JR. 2004. Radiation-induced cognitive impairments are associated with changes in indicators of hippocampal neurogenesis. Radiat Res 162: $39-47$.

Rajan I, Cline HT. 1998. Glutamate receptor activity is required for normal development of tectal cell dendrites in vivo. J Neurosci 18: 7836-7846.

Rolls ET. 2013. The mechanisms for pattern completion and pattern separation in the hippocampus. Front Syst Neurosci 7: 74 .

Rossi C, Angelucci A, Costantin L, Braschi C, Mazzantini M, Babbini F, Fabbri ME, Tessarollo L, Maffei L, Berardi N, et al. 2006. Brain-derived neurotrophic factor (BDNF) is required for the enhancement of hippocampal neurogen- esis following environmental enrichment. Eur J Neurosci 24: $1850-1856$.

Sahay A, Scobie KN, Hill AS, O'Carroll CM, Kheirbek MA, Burghardt NS, Fenton AA, Dranovsky A, Hen R. 2011 Increasing adult hippocampal neurogenesis is sufficient to improve pattern separation. Nature 472: 466-470.

Sandoval CJ, Martinez-Claros M, Bello-Medina PC, Perez O, Ramirez-Amaya V. 2011. When are new hippocampal neurons, born in the adult brain, integrated into the network that processes spatial information? PLOS ONE 6: e17689.

Saxe MD, Battaglia F, Wang JW, Malleret G, David DJ, Monckton JE, Garcia AD, Sofroniew MV, Kandel ER, Santarelli L, et al. 2006. Ablation of hippocampal neurogenesis impairs contextual fear conditioning and synaptic plasticity in the dentate gyrus. Proc Natl Acad Sci 103: 17501-17506.

Saxe MD, Malleret G, Vronskaya S, Mendez I, Garcia AD, Sofroniew MV, Kandel ER, Hen R. 2007. Paradoxical influence of hippocampal neurogenesis on working memory. Proc Natl Acad Sci 104: 4642-4646.

Selemon LD. 2013. A role for synaptic plasticity in the adolescent development of executive function. Transl Psychiatry 3: e238.

Shors TJ, Miesegaes G, Beylin A, Zhao M, Rydel T, Gould E. 2001. Neurogenesis in the adult is involved in the formation of trace memories. Nature 410: 372-376.

Shors TJ, Townsend DA, Zhao M, Kozorovitskiy Y, Gould E. 2002. Neurogenesis may relate to some but not all types of hippocampal-dependent learning. Hippocampus 12: $578-584$.

Sin WC, Haas K, Ruthazer ES, Cline HT. 2002. Dendrite growth increased by visual activity requires NMDA receptor and Rho GTPases. Nature 419: 475-480.

Snyder JS, Kee N, Wojtowicz JM. 2001. Effects of adult neurogenesis on synaptic plasticity in the rat dentate gyrus. J Neurophysiol 85: 2423-2431.

Snyder JS, Hong NS, McDonald RJ, Wojtowicz JM. 2005. A role for adult neurogenesis in spatial long-term memory. Neuroscience 130: 843-852.

Song J, Zhong C, Bonaguidi MA, Sun GJ, Hsu D, Gu Y, Meletis K, Huang ZJ, Ge S, Enikolopov G, et al. 2012. Neuronal circuitry mechanism regulating adult quiescent neural stem-cell fate decision. Nature 489: 150-154.

Song J, Sun J, Moss J, Wen Z, Sun GJ, Hsu D, Zhong C, Davoudi H, Christian KM, Toni N, et al. 2013. Parvalbumin interneurons mediate neuronal circuitry-neurogenesis coupling in the adult hippocampus. Nat Neurosci 16: $1728-1730$.

Spear LP. 2009. Heightened stress responsivity and emotional reactivity during pubertal maturation: Implications for psychopathology. Dev Psychopathol 21: 87-97.

Stanley DP, Shetty AK. 2004. Aging in the rat hippocampus is associated with widespread reductions in the number of glutamate decarboxylase- 67 positive interneurons but not interneuron degeneration. J Neurochem 89: 204-216.

Steele RJ, Morris RG. 1999. Delay-dependent impairment of a matching-to-place task with chronic and intrahippocampal infusion of the NMDA-antagonist D-AP5. Hippocampus 9: 118-136. 
Stone SS, Teixeira CM, Devito LM, Zaslavsky K, Josselyn SA, Lozano AM, Frankland PW. 2011a. Stimulation of entorhinal cortex promotes adult neurogenesis and facilitates spatial memory. J Neurosci 31: 13469-13484.

Stone SS, Teixeira CM, Zaslavsky K, Wheeler AL, MartinezCanabal A, Wang AH, Sakaguchi M, Lozano AM, Frankland PW. 2011b. Functional convergence of developmentally and adult-generated granule cells in dentate gyrus circuits supporting hippocampus-dependent memory. Hippocampus 21: 1348-1362.

Tashiro A, Makino H, Gage FH. 2007. Experience-specific functional modification of the dentate gyrus through adult neurogenesis: A critical period during an immature stage. J Neurosci 27: 3252-3259.

Teixeira CM, Pomedli SR, Maei HR, Kee N, Frankland PW. 2006. Involvement of the anterior cingulate cortex in the expression of remote spatial memory. J Neurosci 26: 7555-7564.

Touyarot K, Bonhomme D, Roux P, Alfos S, Lafenetre P, Richard E, Higueret P, Pallet V. 2013. A mid-life vitamin A supplementation prevents age-related spatial memory deficits and hippocampal neurogenesis alterations through CRABP-I. PLoS ONE 8: e72101.

Treves A, Rolls ET. 1992. Computational constraints suggest the need for two distinct input systems to the hippocampal CA3 network. Hippocampus 2: 189-199.

Tronel S, Fabre A, Charrier V, Oliet SH, Gage FH, Abrous DN. 2010. Spatial learning sculpts the dendritic arbor of adult-born hippocampal neurons. Proc Natl Acad Sci 107: $7963-7968$

Tronel S, Belnoue L, Grosgean N, Revest JM, Piazza PV, Koehl M, Abrous DN. 2012. Adult-born neurons are necessary for extended contextual discrimination. Hippocampus 22: 292-298.

Tronel S, Lemaire V, Charrier V, Montaron MF, Abrous DN. 2014. Influence of ontogenetic age on the role of dentate granule neurons. Brain Struct Funct doi: 10.1007/s00429014-0715-y.

Trouche S, Bontempi B, Roullet P, Rampon C. 2009. Recruitment of adult-generated neurons into functional hippocampal networks contributes to updating and strengthening of spatial memory. Proc Natl Acad Sci 106: 59195924.

Van der Borght K, Meerlo P, Luiten PG, Eggen BJ, Van der Zee EA. 2005. Effects of active shock avoidance learning on hippocampal neurogenesis and plasma levels of corticosterone. Behav Brain Res 157: 23-30.

van Praag H, Christie BR, Sejnowski TJ, Gage FH. 1999a. Running enhances neurogenesis, learning, and longterm potentiation in mice. Proc Natl Acad Sci 96: $13427-13431$.
Neurogenesis and Hippocampal Memory System

van Praag H, Kempermann G, Gage FH. 1999b. Running increases cell proliferation and neurogenesis in the adult mouse dentate gyrus. Nat Neurosci 2: 266-270.

van Praag H, Shubert T, Zhao C, Gage FH. 2005. Exercise enhances learning and hippocampal neurogenesis in aged mice. J Neurosci 25: 8680-8685.

Vivar C, Potter MC, Choi J, Lee JY, Stringer TP, Callaway EM, Gage FH, Suh H, van Praag H. 2012. Monosynaptic inputs to new neurons in the dentate gyrus. Nat Commun 3: 1107.

Vukovic J, Borlikova GG, Ruitenberg MJ, Robinson GJ, Sullivan RK, Walker TL, Bartlett PF. 2013. Immature doublecortin-positive hippocampal neurons are important for learning but not for remembering. J Neurosci 33: 66036613.

Wei L, Meaney MJ, Duman RS, Kaffman A. 2011. Affiliative behavior requires juvenile, but not adult neurogenesis. J Neurosci 31: 14335-14345.

Whissell PD, Rosenzweig S, Lecker I, Wang DS, Wojtowicz JM, Orser BA. 2013. $\gamma$-Aminobutyric acid type A receptors that contain the $\delta$ subunit promote memory and neurogenesis in the dentate gyrus. Ann Neurol 74: 611621.

Wilson IA, Gallagher M, Eichenbaum H, Tanila H. 2006. Neurocognitive aging: Prior memories hinder new hippocampal encoding. Trends Neurosci 29: 662-670.

Winocur G, Moscovitch M, Fogel S, Rosenbaum RS, Sekeres M. 2005. Preserved spatial memory after hippocampal lesions: Effects of extensive experience in a complex environment. Nat Neurosci 8: 273-275.

Winocur G, Wojtowicz JM, Sekeres M, Snyder JS, Wang S. 2006. Inhibition of neurogenesis interferes with hippocampus-dependent memory function. Hippocampus 16: 296-304.

Winocur G, Becker S, Luu P, Rosenzweig S, Wojtowicz JM. 2012. Adult hippocampal neurogenesis and memory interference. Behav Brain Res 227: 464-469.

Wiskott L, Rasch MJ, Kempermann G. 2006. A functional hypothesis for adult hippocampal neurogenesis: Avoidance of catastrophic interference in the dentate gyrus. Hippocampus 16: 329-343.

Witter MP. 1993. Organization of the entorhinal-hippocampal system: A review of current anatomical data. Hippocampus 3: 33-44.

Wojtowicz JM, Askew ML, Winocur G. 2008. The effects of running and of inhibiting adult neurogenesis on learning and memory in rats. Eur J Neurosci 27: 1494-1502.

Xavier GF, Oliveira-Filho FJB, Santos AMG. 1999. Dentate gyrus-selective colchicine lesion and disruption of performance in spatial tasks: Difficulties in place "strategy" because of a lack of flexibility in the use of environmental cues? Hippocampus 9: 668-681. 


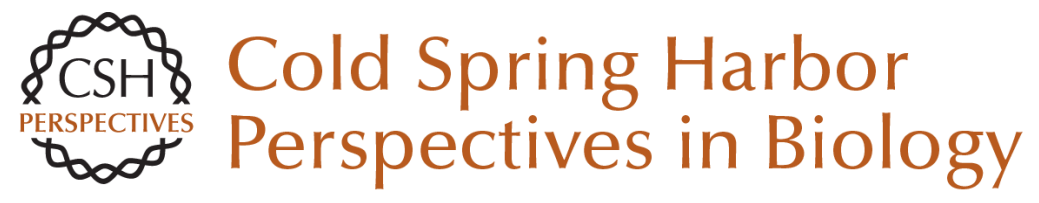

\section{Interaction between Neurogenesis and Hippocampal Memory System: New Vistas}

Djoher Nora Abrous and Jan Martin Wojtowicz

Cold Spring Harb Perspect Biol 2015; doi: 10.1101/cshperspect.a018952

\section{Subject Collection Neurogenesis}

Adult Neurogenesis and Psychiatric Disorders

Eunchai Kang, Zhexing Wen, Hongjun Song, et al.

Neuronal Circuitry Mechanisms Regulating Adult

Mammalian Neurogenesis Juan Song, Reid H.J. Olsen, Jiaqi Sun, et al.

Neurogenesis in the Developing and Adult Brain

--Similarities and Key Differences

Magdalena Götz, Masato Nakafuku and David Petrik

Genetics and Epigenetics in Adult Neurogenesis Jenny Hsieh and Xinyu Zhao

The Adult Ventricular-Subventricular Zone (V-SVZ) and Olfactory Bulb (OB) Neurogenesis Daniel A. Lim and Arturo Alvarez-Buylla

Diversity of Neural Precursors in the Adult Mammalian Brain

Michael A. Bonaguidi, Ryan P. Stadel, Daniel A. Berg, et al.

Detection and Phenotypic Characterization of Adult Neurogenesis H. Georg Kuhn, Amelia J. Eisch, Kirsty Spalding, et al.

Maturation and Functional Integration of New Granule Cells into the Adult Hippocampus Nicolas Toni and Alejandro F. Schinder
Adult Olfactory Bulb Neurogenesis

Pierre-Marie Lledo and Matt Valley

Adult Neurogenesis in Fish Julia Ganz and Michael Brand

In Vitro Models for Neurogenesis Hassan Azari and Brent A. Reynolds

\section{Engineering of Adult Neurogenesis and Gliogenesis \\ Benedikt Berninger and Sebastian Jessberger \\ Computational Modeling of Adult Neurogenesis James B. Aimone \\ Control of Adult Neurogenesis by Short-Range Morphogenic-Signaling Molecules Youngshik Choe, Samuel J. Pleasure and Helena Mira}

Adult Neurogenesis: An Evolutionary Perspective Gerd Kempermann

\section{Epilepsy and Adult Neurogenesis} Sebastian Jessberger and Jack M. Parent

For additional articles in this collection, see http://cshperspectives.cshlp.org/cgi/collection/

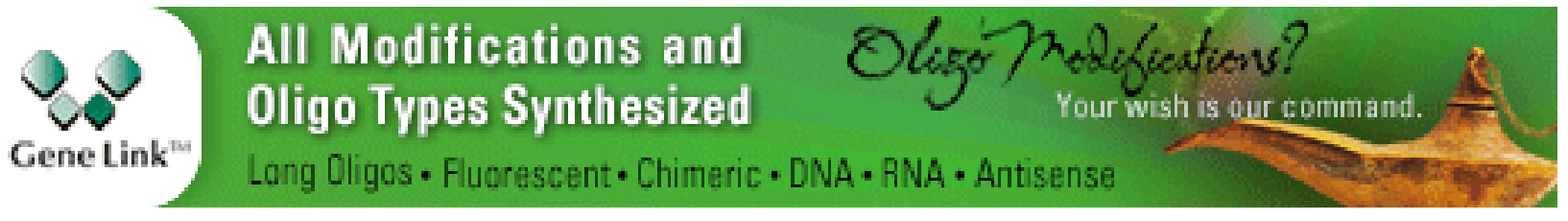


For additional articles in this collection, see http://cshperspectives.cshlp.org/cgi/collection/

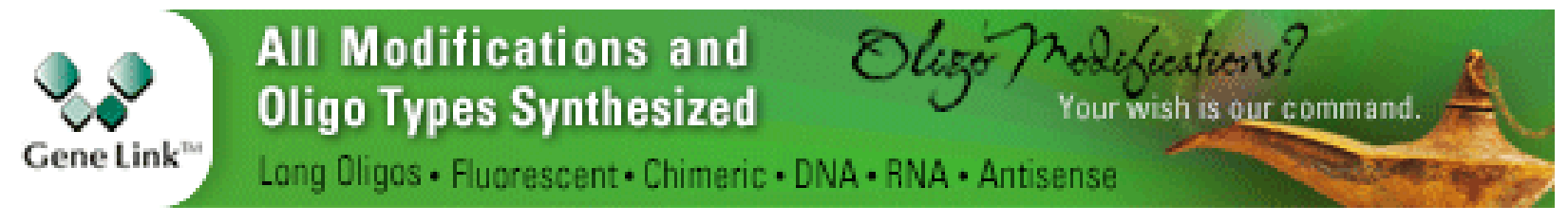

Copyright @ 2015 Cold Spring Harbor Laboratory Press; all rights reserved 